\title{
The extreme space weather event in September 1909
}

\author{
Hisashi Hayakawa, Yusuke Ebihara, Edward W. Cliver, \\ Kentaro Hattori, Shin Toriumi, Jeffrey J. Love, Norio Umemura, \\ Kosuke Namekata, Takahito Sakaue, Takuya Takahashi and \\ Kazunari Shibata
}

\section{Published version information}

Citation: H Hayakawa et al. "The extreme space weather event in September 1909." Monthly Notices of the Royal Astronomical Society, vol. 484, no. 3 (2019): 40834099 .

DOI: $\underline{10.1093 / \mathrm{mnras} / \mathrm{sty} 3196}$

(C)2018 The Authors. Published by Oxford University Press on behalf of the Royal Astronomical Society. All rights reserved.

This version is made available in accordance with publisher policies. Please cite only the published version using the reference above. This is the citation assigned by the publisher at the time of issuing the APV. Please check the publisher's website for any updates. 


\title{
The extreme space weather event in September 1909
}

\author{
Hisashi Hayakawa ${ }^{\oplus},{ }^{1,2 \star} \dagger$ Yusuke Ebihara, ${ }^{3,4}$ Edward W. Cliver, ${ }^{5}$ Kentaro Hattori, ${ }^{6}$ \\ Shin Toriumi,${ }^{7} \ddagger$ Jeffrey J. Love, ${ }^{8}$ Norio Umemura, ${ }^{9}$ Kosuke Namekata, ${ }^{6}$ \\ Takahito Sakaue, ${ }^{6,10}$ Takuya Takahashi ${ }^{6,10}$ and Kazunari Shibata ${ }^{6,10}$ \\ ${ }^{1}$ Graduate School of Letters, Osaka University, 5600043 Toyonaka, Japan \\ ${ }^{2}$ Science and Technology Facilities Council, RAL Space, Rutherford Appleton Laboratory, Harwell Campus, Didcot OX11 0QX, UK \\ ${ }^{3}$ Research Institute for Sustainable Humanosphere, Kyoto University, Uji 6100011, Japan \\ ${ }^{4}$ Unit of Synergetic Studies for Space, Kyoto University, Kyoto 6068306, Japan \\ ${ }^{5}$ National Solar Observatory, 3665 Discovery Drive, Boulder, CO 80303, USA \\ ${ }^{6}$ Graduate School of Science, Kyoto University, Kyoto, Kitashirakawa Oiwake-cho, Sakyo-ku, Kyoto 6068502, Japan \\ ${ }^{7}$ National Astronomical Observatory of Japan, 1818588 Mitaka, Japan \\ ${ }^{8}$ Geomagnetism Program, U.S. Geological Survey, Box 25046 MS 966 DFC, Denver, CO 802256, USA \\ ${ }^{9}$ Institute for Space-Earth Environmental Research, Nagoya University, 4648601 Nagoya, Japan \\ ${ }^{10}$ Kwasan Observatory, Kyoto University, 6078471 Kyoto, Japan
}

Accepted 2018 November 19. Received 2018 November 9; in original form 2018 September 22

\begin{abstract}
We evaluate worldwide low-latitude auroral activity associated with the great magnetic storm of September 1909 for which a minimum Dst value of $-595 \mathrm{nT}$ has recently been determined. From auroral observations, we calculate that the equatorward boundary of the auroral oval in the 1909 event was in the range from $31^{\circ}-35^{\circ}$ invariant latitude (assuming auroral height of $400 \mathrm{~km})$ to $37^{\circ}-38^{\circ}(800 \mathrm{~km})$. These locations compare with satellite-based observations of precipitating auroral electrons down to $40^{\circ}$ magnetic latitude for the March 1989 storm with its comparable minimum Dst value of $-589 \mathrm{nT}$. According to Japanese auroral records, bluish colour started to appear first, followed by reddish colour. The colour change can be attributed to the transition from sunlit aurora to the usual low-latitude reddish aurora. Telegraph communications were disrupted at mid/low latitudes, coincidently with the storm main phase and the early recovery phase. The telegraphic disturbances were caused by geomagnetically induced currents associated with the storm-time ring current and substorm current wedge. From the calculated CME energy - based on the $24.75 \mathrm{hr}$ separation between the flare-associated magnetic crochet and the geomagnetic storm sudden commencement and interplanetary conditions inferred from geomagnetic data - and consideration of the $\sim-40 \mathrm{nT}$ crochet amplitude, we estimated that the soft X-ray class of the 24 September 1909 flare was $\geq X 10$. As is the case for other extreme storms, strong/sharp excursions in the horizontal component of the magnetic field observed at low-latitude magnetic stations were coincident with the observation of low-latitude aurora.
\end{abstract}

Key words: Sun: coronal mass ejections (CMEs) - (Sun:) solar-terrestrial relations - (Sun:) sunspots - planets and satellites: aurorae - planets and satellites: magnetic fields - Sun: flares.

\section{INTRODUCTION}

Documenting intense magnetic storms driven by solar disturbances is important (e.g. Hale 1931; Newton 1943; Gosling et al. 1991; Gonzalez et al. 1994; Daglis, 2000, 2004; Vaquero \& Vazquez

\footnotetext{
^E-mail: hisashi.hayakawa@stfc.ac.uk; hayakawa@kwasan.kyoto-u.ac.jp $\dagger$ JSPS Research Fellow

$\ddagger$ NAOJ Fellow
}

2009; Odenwald 2015; Knipp et al. 2016; Lefèvre et al. 2016; Lockwood et al. 2016, 2018; Usoskin 2017; Riley et al. 2018) in order to understand, and therefore predict, the circumstances under which they arise and to quantify and prepare for their consequences on our increasingly technology-based society. The exemplar for great geomagnetic storms is the Carrington event in September 1859 (Carrington 1860; Hodgson 1860; Stewart 1861; Bartels 1937; Tsurutani et al. 2003; Cliver \& Svalgaard 2004; Siscoe et al. 2006; Usoskin and Kovaltsov 2012; Cliver \& Dietrich 2013; Lakhina \& Tsurutani 2016). This event was associated with auroral displays 
observed down to $20^{\circ} \sim 23^{\circ}$ magnetic latitude (hereafter, MLAT) (Loomis 1861; Kimball 1960; Green \& Boardsen 2006; Hayakawa et al. 2016b).

The primary impact of the 1859 storm was on telegraphy (e.g. Boteler 2006). Today the principal 'space weather' threat is to the electric power grid (Baker et al. 2008; Hapgood, 2011, 2012; Oughton et al. 2016; Dyer et al. 2018). Because of this threat, several studies have been carried out to estimate how frequently such extreme space weather events may occur (e.g. Tsubouchi \& Omura 2007; Riley 2012; Curto, Castell \& Del Moral 2016; Riley $\&$ Love 2017). Such studies are dependent on the observations of a handful of storms that have approached or rivalled the Carrington geomagnetic storm in observed/inferred intensity and/or auroral extent. These include great storms in February 1872 (Chapman 1957a,b; Silverman 2008; Hayakawa et al. 2018c); September 1909 (Silverman 1995; Willis, Stephenson \& Fang 2007; Love et al. 2019); May 1921 (Silverman \& Cliver 2001; Kappenman 2006; Cliver \& Dietrich 2013). The only such storm observed during the space era occurred in March 1989 (Allen et al. 1989; Silverman 2006a; Pulkkinen et al. 2012; Cid et al. 2014). More recently, in July 2012, a major backside eruption on the Sun was observed both remotely and in situ by the STEREO spacecraft (Kaiser et al. 2008; Russell et al. 2013; Liu et al. 2014; Riley et al. 2016). The interplanetary coronal mass ejection (CME) propagated to $1 \mathrm{AU}$ in $\sim 20$ h. Baker et al. (2013) calculated that had the eruption occurred on the frontside of the Sun - with optimal seasonal and local timing to maximize solar wind - magnetosphere coupling (worst case scenario (see e.g. Temerin \& Li 2002) - it might have produced a storm greater than that inferred for the Carrington event. In addition to these storms, auroral evidence has recently been provided for two pre-1859 storms that may have ranked with the Carrington event: February 1730 (Hayakawa et al. 2018a), and, particularly, September 1770 (Willis et al. 1996; Nakazawa, Okada \& Shiokawa 2004; Ebihara et al. 2017; Hayakawa et al. 2017e).

Among these seven candidates of extreme storms (i.e. 1730, $1770,1859,1872,1909,1921$, and 1989), we focus here on the event in September 1909. Chapman (1957a,b) noted a visual report of aurorae for this event from Singapore $\left(-10.0^{\circ}\right.$ MLAT). However, Silverman (1995), based on an examination of contemporary records, discounted the observation from Singapore - attributing it to a conflation of the impact on telegraph traffic at that site to a local observation of aurorae. Silverman (1995) did note that aurorae were reported at $28^{\circ}$ MLAT from Japan. Recently, Love, Hayakawa \& Cliver (2019) have used geomagnetic records from Spain (Azcárate 1910), Puerto Rico (Hazard 1912), Western Samoa (Wegener 1914), and Mauritius (Claxton \& Walter 1913) to deduce a Dst value of $-595 \mathrm{nT}$ for the 1909 storm, making it comparable to the $-589 \mathrm{nT}$ storm of March 1989, the most intense storm of the space age.

In this study, we revisit the auroral observations of the September 1909 magnetic storm to reconstruct the equatorward boundary of the auroral oval. We then compare the timing of the aurorae at low latitudes with the magnetometer traces from Love, Hayakawa \& Cliver (2019). In addition, from observations of the solar flare effect (SFE; also referred to as 'magnetic crochet') and storm sudden commencement for the 1909 event, we infer the size of the associated flare.

\section{DATA AND METHODOLOGY}

In order to estimate the equatorward boundary of the auroral oval for the September 1909 event, we examine contemporary reports of visual aurorae in Japan, from where Silverman (1995) considered the most reliable reports of low-latitude auroral activity to have originated. Both Silverman (1995) and Willis, Stephenson \& Fang (2007) based their analyses on records from Tenmon Geppou (Astronomical Herald), a news magazine of the Astronomical Society of Japan. Here we examined contemporary reports of the central meteorological observatory of Japan and newspapers previously unexamined. We extracted information of the observational time, direction, location, and maximum elevation angle (as available) for each reported auroral sighting. We computed the contemporary MLAT of each observational site with the magnetic field model IGRF12 (Thébault et al. 2015). We then applied triangulation for their MLAT and elevation angle to reconstruct the equatorward boundary of the auroral oval (i.e. the MLAT of the auroral oval). For magnetic observations of the flare-associated geomagnetic crochet, the storm sudden commencement, and the evolution of the magnetic storm, we relied on the recent analysis of Love, Hayakawa \& Cliver (2019).

To examine the solar source of the 1909 storm, we used contemporary sunspot drawings from Kalocsa Observatory (Hungary) available in the data base of the Debrecen Observatory (Hungary) and flare reports by contemporary British observers. Fortunately, observations of the solar eruption likely responsible for the storm were provided by Lockyer (1909) and others, as synthesized by Hale (1931). The magnetic observations summarized in Love, Hayakawa \& Cliver (2019) of SFE timing/amplitude and SC timing allow us to infer the CME speed and to constrain the intensity of the flare soft X-ray (SXR) burst, a common measure of flare size, following Cliver \& Svalgaard (2004). We also estimated the lower limit of CME kinetic energy and SXR class of the associated flare from the CME propagation time.

\section{EQUATORWARD BOUNDARY OF AURORAL OVAL}

In this section, we concentrate on reconstruction of the equatorward boundary of the auroral oval (or the auroral emission region). The sites considered in the following subsections are those from which aurorae were observed, such sites can be well-equatorward of the position of the auroral oval. They are shown on the map in Fig. 1 with MLAT from the magnetic equator in 1909. We focus only on the sites at which the absolute value of MLAT is less than $40^{\circ}$. The coordinates of the sites and details of the auroral records at each site are given in Table 1.

\subsection{Observations from Japan}

Silverman (1995) and Willis, Stephenson \& Fang (2007), citing the auroral catalogue of Kanda (1933, p. 208) published in Tenmon Geppo for Japanese records, noted observational sites at Niigata, Akita, and Hakodate. Kanda (1933) wrote, 'This occurrence was a famous thing, since it was visible in various areas of Hokkaidō, Akita, and Niigata. It was recorded in various newspapers of the time. Mr. Saweda Tanejiro's [NB Sawada Tanejiro in the original text] sketches from the sea towards Hakodate [Hokkaidō Prefecture] and his observations are recorded on page 132 of issue 21 of this journal' (Kanda 1933, p.208; Willis, Stephenson \& Fang 2007, p.434). Obviously, Kanda (1933) is not a primary source document and is based on 'newspapers' and 'Mr Saweda Tanejiro's sketches ... and his observations' (Sawada $1928=\mathrm{J} 1-1$ ). Therefore, we only consider Sawada (1928), as the newspapers that Kanda (1933) relied upon are not specified, and revise Sawada's observational site as Otobe, according to his other report in $\mathrm{J} 12$ (N41 $58^{\prime}, 140^{\circ} 07^{\prime}$; 


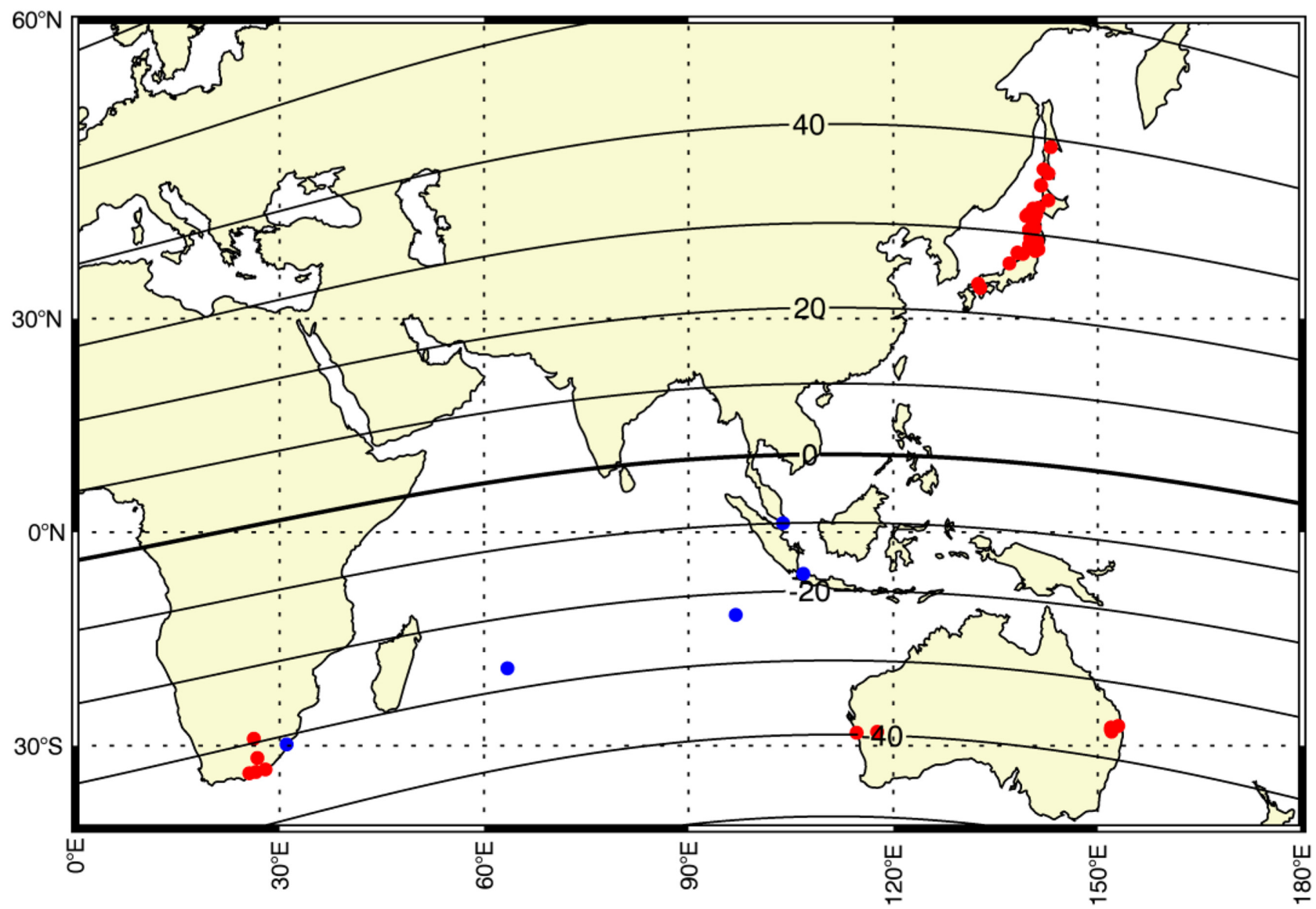

Figure 1. Distribution of auroral observational sites within $\pm 40^{\circ}$ MLAT. The blue dots show the observational sites based on the hearsay account in Nature (v.81, p.524), such as Singapore.

$31.8^{\circ}$ MLAT). On the other hand, we have further reports in Tenmon Geppou (J1-2 1-5) and reproductions of the Japanese reports to the central meteorological observatory of Japan and newspapers written in Japanese (J2 and J3). In these, we find not only Akita and Niigata, but also other observational sites down to Matsuyama $\left(\mathrm{N} 33^{\circ} 51^{\prime}, \mathrm{E} 132^{\circ} 47^{\prime}\right)$. We have several newspaper articles (J4 J7, $\mathrm{J} 9 \sim \mathrm{J} 11$ ) with little variation of description, presumably by different observers. One of the most important of these newspaper accounts is J7 (Chugoku Shinbun), reporting auroral observation in Hiroshima $\left(\mathrm{N} 34^{\circ} 22^{\prime}, \mathrm{E} 132^{\circ} 28^{\prime}\right)$ and reproduced in J8. Thus, Table 1 and Fig. 1 show auroral visibility was more widely spread than the three known observational sites in Silverman (1995) and Willis, Stephenson \& Fang (2007).

We computed the MLAT of each observational site as summarized in Table 1 based on the magnetic field model IGRF12 (Thébault et al. 2015). According to Thébault et al. (2015), the geomagnetic north pole, namely the location where the dipole axis intersects the Earth's surface, was at N78.59 , W68.73 in 1909. The corresponding observational sites in Japanese territory are distributed from Shisuka (current Polonaysk: N49 ${ }^{\circ} 14^{\prime}, \mathrm{E} 143^{\circ} 07^{\prime}$; $39.2^{\circ}$ MLAT) to Matsuyama (N33 ${ }^{\circ} 51^{\prime}$, E132 $47^{\prime} ; 23.2^{\circ}$ MLAT) and Hiroshima $\left(\mathrm{N} 34^{\circ} 22^{\prime}, \mathrm{E} 132^{\circ} 28^{\prime} ; 23.6^{\circ}\right.$ MLAT). Note that the southern half of Sakhalin (Karafuto) Island was under the rule of the Japanese Empire in 1909.

The lowest latitude locations at which aurorae were reported in Japan are similar to the equatorward extension of auroral visibility in the Carrington storm. In that storm, the auroral visibility was distributed down to $\sim 20^{\circ}-23^{\circ}$ MLAT (Kimball 1960; Tsurutani et al. 2003; Hayakawa et al. 2016b). Green \& Boardsen (2006) found ship logs (Saranac, Sabine, and St. Mary) describing the low-latitude aurora in September 1859. According to the location of the geomagnetic north pole at that time in the geomagnetic field model of GUFM1 (Jackson et al. 2000), the shipboard observations were made at $20.2^{\circ}, 23.1^{\circ}$, and $23.0^{\circ}$ MLATs, respectively, while the report by Saranac is rather associated with the preceding August storm (Hayakawa et al. 2018b).

The elevation angle of the auroral display provides valuable information to estimate the equatorward boundary of the auroral oval. Fortunately, for the 1909 event, several Japanese records include the elevation angle of the aurorae at the maximum phase of the storm. Here, we compute not only MLAT but also invariant latitude (ILAT) as shown in Fig. 2. The ILAT is a parameter for the magnetic field line, and is the same along the magnetic field line (O'Brien et al. 1962). In case of the dipole magnetic field, the ILAT is identical to the MLAT on the surface of the Earth, while the MLAT is different from the ILAT above the ground. Since the electrons trapped by a magnetic field line tend to move along a field line, the ILAT is a better parameter to identify the magnetic field line that traps electrons resulting in the auroral brightening. Here we calculate the ILAT at altitudes of $400 \mathrm{~km}$ (Silverman 1998; Ebihara et al. 2017) and $800 \mathrm{~km}$ (Loomis 1861).

Reports from Matsuyama, the most equatorward observational site in Japan, show that the auroral display extended ' $30^{\circ}$ above 
Table 1. Auroral observations on 25 September 1909 within $\pm 40^{\circ}$ MLAT, based on the references shown in the Appendix.

\begin{tabular}{|c|c|c|c|c|c|c|c|c|c|c|c|c|c|}
\hline \multirow[b]{2}{*}{ ID } & \multirow[b]{2}{*}{ Colour } & \multirow[b]{2}{*}{ Direction } & \multicolumn{2}{|c|}{ Start LT } & \multicolumn{2}{|c|}{ End LT } & \multirow[b]{2}{*}{$\mathrm{N} / \mathrm{S}$} & \multirow{2}{*}{$\begin{array}{l}\text { Lat. } \\
\text { deg }\end{array}$} & \multirow[b]{2}{*}{$\min$} & \multicolumn{3}{|c|}{ Long. } & \multirow[b]{2}{*}{ MLAT } \\
\hline & & & $\mathrm{h}$ & $\mathrm{m}$ & $\mathrm{h}$ & $\mathrm{m}$ & & & & $\mathrm{E} / \mathrm{W}$ & deg & $\min$ & \\
\hline $\mathrm{J} 1-2$ & $\mathrm{R}$ & $\mathrm{n}$ & 25 & 0 & 25 & 30 & $\mathrm{~N}$ & 37 & 55 & $\mathrm{E}$ & 139 & 2 & 27.7 \\
\hline $\mathrm{J} 1-3$ & $\mathrm{R}$ & $\mathrm{n}$ & 25 & 0 & 28 & 0 & $\mathrm{~N}$ & 38 & 55 & $\mathrm{E}$ & 139 & 55 & 28.7 \\
\hline $\mathrm{J} 1-4$ & W-BW-R & $\mathrm{n}$ & 24 & 0 & 29 & 0 & $\mathrm{~N}$ & 42 & 23 & $\mathrm{E}$ & 139 & 49 & 32.2 \\
\hline $\mathrm{J} 1-5$ & $\mathrm{R}$ & nw-ne & 23 & 0 & 27 & 0 & $\mathrm{~N}$ & 43 & 4 & $\mathrm{E}$ & 141 & 20 & 33.0 \\
\hline $\mathrm{J} 2-2$ & Y & e-w & 23 & 0 & 26 & 0 & $\mathrm{~N}$ & 46 & 38 & $\mathrm{E}$ & 142 & 47 & 36.6 \\
\hline $\mathrm{J} 2-3$ & - & $\mathrm{n}$ & 23 & 0 & - & - & $\mathrm{N}$ & 49 & 14 & $\mathrm{E}$ & 143 & 7 & 39.2 \\
\hline $\mathrm{J} 2-4$ & WR & $\mathrm{n}$ & 23 & 0 & 26 & 0 & $\mathrm{~N}$ & 47 & 3 & $\mathrm{E}$ & 142 & 3 & 37.0 \\
\hline $\mathrm{J} 2-5$ & Pi & ne-nw & 25 & 0 & 26 & 0 & $\mathrm{~N}$ & 41 & 46 & $\mathrm{E}$ & 140 & 43 & 31.6 \\
\hline $\mathrm{J} 2-6$ & R-RO & - & 25 & 45 & 26 & 15 & $\mathrm{~N}$ & 38 & 26 & $\mathrm{E}$ & 141 & 18 & 28.4 \\
\hline $\mathrm{J} 2-7$ & $\mathrm{R}$ & - & 23 & 0 & 27 & 0 & $\mathrm{~N}$ & 37 & 55 & $\mathrm{E}$ & 139 & 2 & 27.7 \\
\hline $\mathrm{J} 3-4$ & $\mathrm{RY}$ & nw-ne & 22 & 40 & 23 & 45 & $\mathrm{~N}$ & 43 & 4 & $\mathrm{E}$ & 141 & 20 & 33.0 \\
\hline $\mathrm{J} 3-5$ & R/Y/BW & ne-nw & 22 & 40 & - & - & $\mathrm{N}$ & 43 & 4 & $\mathrm{E}$ & 141 & 20 & 33.0 \\
\hline J3-6 & RPu-Y & - & 24 & 0 & - & - & $\mathrm{N}$ & 43 & 4 & $\mathrm{E}$ & 141 & 20 & 33.0 \\
\hline $\mathrm{J} 3-7$ & $\mathrm{R}$ & nne-nww & 23 & 0 & 27 & 0 & $\mathrm{~N}$ & 42 & 10 & $\mathrm{E}$ & 139 & 31 & 31.9 \\
\hline $\mathrm{J} 3-8$ & W-BW-R & $\mathrm{n}$ & 24 & 0 & 29 & 0 & $\mathrm{~N}$ & 42 & 23 & $\mathrm{E}$ & 139 & 49 & 32.2 \\
\hline J3-9 & Pi-R & nw-e & 25 & 0 & 27 & 0 & $\mathrm{~N}$ & 42 & 26 & $\mathrm{E}$ & 140 & 0 & 32.2 \\
\hline J3-10 & $\mathrm{R}$ & nw & - & - & - & - & $\mathrm{N}$ & 42 & 59 & $\mathrm{E}$ & 140 & 31 & 32.8 \\
\hline J3-11 & $\mathrm{R}-\mathrm{W}$ & $\mathrm{n}$ & 25 & 30 & - & - & $\mathrm{N}$ & 42 & 20 & $\mathrm{E}$ & 140 & 59 & 32.2 \\
\hline $\mathrm{J} 3-12$ & $\mathrm{R}-\mathrm{Pi}$ & nw-ne & 23 & 0 & 27 & 0 & $\mathrm{~N}$ & 42 & 19 & $\mathrm{E}$ & 140 & 59 & 32.2 \\
\hline $\mathrm{J} 3-13$ & W & $\mathrm{n}$ & 23 & 30 & - & - & $\mathrm{N}$ & 42 & 35 & $\mathrm{E}$ & 140 & 58 & 32.5 \\
\hline J3-14 & $\mathrm{R}$ & ne & - & - & - & - & $\mathrm{N}$ & 45 & 24 & $\mathrm{E}$ & 141 & 42 & 35.3 \\
\hline J3-15 & $\mathrm{R}$ & nw & 23 & 20 & 25 & 30 & $\mathrm{~N}$ & 45 & 27 & $\mathrm{E}$ & 141 & 39 & 35.4 \\
\hline $\mathrm{J} 4$ & $\mathrm{R}$ & $\mathrm{n}$ & 25 & 30 & - & - & $\mathrm{N}$ & 37 & 55 & $\mathrm{E}$ & 139 & 2 & 27.7 \\
\hline J5 & $\mathrm{R}$ & $n-w$ & 25 & 30 & 26 & 30 & $\mathrm{~N}$ & 38 & 26 & $\mathrm{E}$ & 141 & 18 & 28.4 \\
\hline J6 & $\mathrm{R}$ & $\mathrm{n}$ & 25 & 0 & - & - & $\mathrm{N}$ & 37 & 55 & $\mathrm{E}$ & 139 & 2 & 27.7 \\
\hline J6 & $\mathrm{R}$ & nw-ne & 23 & 0 & 27 & 0 & $\mathrm{~N}$ & 43 & 4 & $\mathrm{E}$ & 141 & 20 & 33.0 \\
\hline $\mathrm{J} 7$ & $\mathrm{R}$ & $\mathrm{n}$ & 25 & 30 & 26 & 20 & $\mathrm{~N}$ & 34 & 22 & $\mathrm{E}$ & 132 & 28 & 23.6 \\
\hline J8 & $\mathrm{R}$ & $\mathrm{n}$ & 25 & 30 & 26 & 20 & $\mathrm{~N}$ & 34 & 22 & $\mathrm{E}$ & 132 & 28 & 23.6 \\
\hline J9 & $\mathrm{R}$ & - & - & - & - & - & $\mathrm{N}$ & 38 & 4 & $\mathrm{E}$ & 138 & 14 & 27.7 \\
\hline $\mathrm{J} 10$ & $\mathrm{R}$ & nnw-nne & 23 & 0 & 28 & 0 & $\mathrm{~N}$ & 43 & 4 & $\mathrm{E}$ & 141 & 20 & 33.0 \\
\hline J11 & $\mathrm{R}$ & nnw-nne & 23 & 0 & 28 & 0 & $\mathrm{~N}$ & 43 & 4 & $\mathrm{E}$ & 141 & 20 & 33.0 \\
\hline $\mathrm{J} 12$ & BW-R/W & $\mathrm{n}$ & 23 & 30 & - & - & $\mathrm{N}$ & 41 & 58 & $\mathrm{E}$ & 140 & 7 & 31.8 \\
\hline SA1 & - & - & - & - & - & - & $\mathrm{S}$ & 29 & 7 & $\mathrm{E}$ & 26 & 13 & -29.5 \\
\hline SA2 & - & - & 22 & 0 & - & - & $\mathrm{S}$ & 33 & 28 & $\mathrm{E}$ & 25 & 33 & -33.6 \\
\hline SA3 & $\mathrm{Pi}$ & s-e & 20 & 0 & 20 & 40 & $\mathrm{~S}$ & 33 & 19 & $\mathrm{E}$ & 26 & 31 & -33.6 \\
\hline SA4 & $\mathrm{R}$ & - & - & - & - & - & $S$ & 33 & 0 & $\mathrm{E}$ & 27 & 55 & -33.6 \\
\hline SA5 & - & - & 21 & 30 & 23 & 0 & $\mathrm{~S}$ & 31 & 34 & $\mathrm{E}$ & 26 & 44 & -32.0 \\
\hline AU1 & R/other & sw & 23 & 0 & - & - & $\mathrm{S}$ & 27 & 28 & $\mathrm{E}$ & 153 & 1 & -35.7 \\
\hline AU2 & $\mathrm{R} / \mathrm{Pu} / \mathrm{W}$ & sw-e & 23 & 0 & dawn & dawn & $S$ & 27 & 11 & $\mathrm{E}$ & 151 & 16 & -35.6 \\
\hline AU3 & R/G & $\mathrm{s}$ & 23 & 30 & - & - & $\mathrm{S}$ & 28 & 13 & $\mathrm{E}$ & 152 & 2 & -36.6 \\
\hline AU4 & $\mathrm{G}$ & s & 22 & 0 & 24 & 0 & $\mathrm{~S}$ & 27 & 56 & $\mathrm{E}$ & 151 & 55 & -36.3 \\
\hline AU5 & $\mathrm{W} / \mathrm{B} / \mathrm{G} / \mathrm{Gy} / \mathrm{Y} / \mathrm{Pi}$ & $\mathrm{s}$ & 23 & 15 & 24 & 50 & $\mathrm{~S}$ & 27 & 40 & $\mathrm{E}$ & 151 & 57 & -36.0 \\
\hline AU6 & $\mathrm{G} / \mathrm{R}$ & $\mathrm{s}-\mathrm{Z}$ & 22 & 0 & 24 & 0 & $\mathrm{~S}$ & 28 & 13 & $\mathrm{E}$ & 152 & 2 & -36.6 \\
\hline AU7 & - & - & 20 & 0 & 21 & 0 & $\mathrm{~S}$ & 28 & 21 & $\mathrm{E}$ & 114 & 38 & -39.7 \\
\hline AU8 & - & - & 21 & 45 & 30 & 0 & $\mathrm{~S}$ & 28 & 14 & $\mathrm{E}$ & 117 & 39 & -39.6 \\
\hline N1 & - & - & - & - & - & - & $\mathrm{N}$ & 1 & 20 & $\mathrm{E}$ & 103 & 50 & -10.0 \\
\hline
\end{tabular}


Table 1 - continued

\begin{tabular}{|c|c|c|c|c|c|c|c|c|c|c|c|c|c|}
\hline ID & Colour & Direction & \multicolumn{2}{|c|}{ Start LT } & \multicolumn{2}{|c|}{ End LT } & $\mathrm{N} / \mathrm{S}$ & \multicolumn{3}{|l|}{ Lat. } & \multicolumn{2}{|l|}{ Long. } & MLAT \\
\hline N3 & - & - & - & - & - & - & $\mathrm{S}$ & 6 & 8 & E & 106 & 49 & -17.5 \\
\hline N4 & - & - & - & - & - & - & $\mathrm{S}$ & 19 & 41 & E & 63 & 25 & -27.1 \\
\hline N5 & - & - & - & - & - & - & $\mathrm{S}$ & 29 & 51 & $\mathrm{E}$ & 31 & 1 & -31.1 \\
\hline
\end{tabular}

Abbreviations: The colours are given by R (red), B (blue), W (white), Y (yellow), Pi (pink), Gy (grey), and Pu (purple). The directions are given with the eight points of compass. The references for the stations here (e.g. J1-1, SA1, AU1, or N1) are given in the Appendix. Their dates are all on 25 September 1909 . The observational time is given in a local standard time between 06:00 and 30:00 (06:00 on the following day) to describe the observational time beyond midnight continuously with local time $+24 \mathrm{~h}$ on the same date (e.g. 25:00 on 25 September for 01:00 on 26 September) as in Hayakawa et al. (2017e, 2018b).

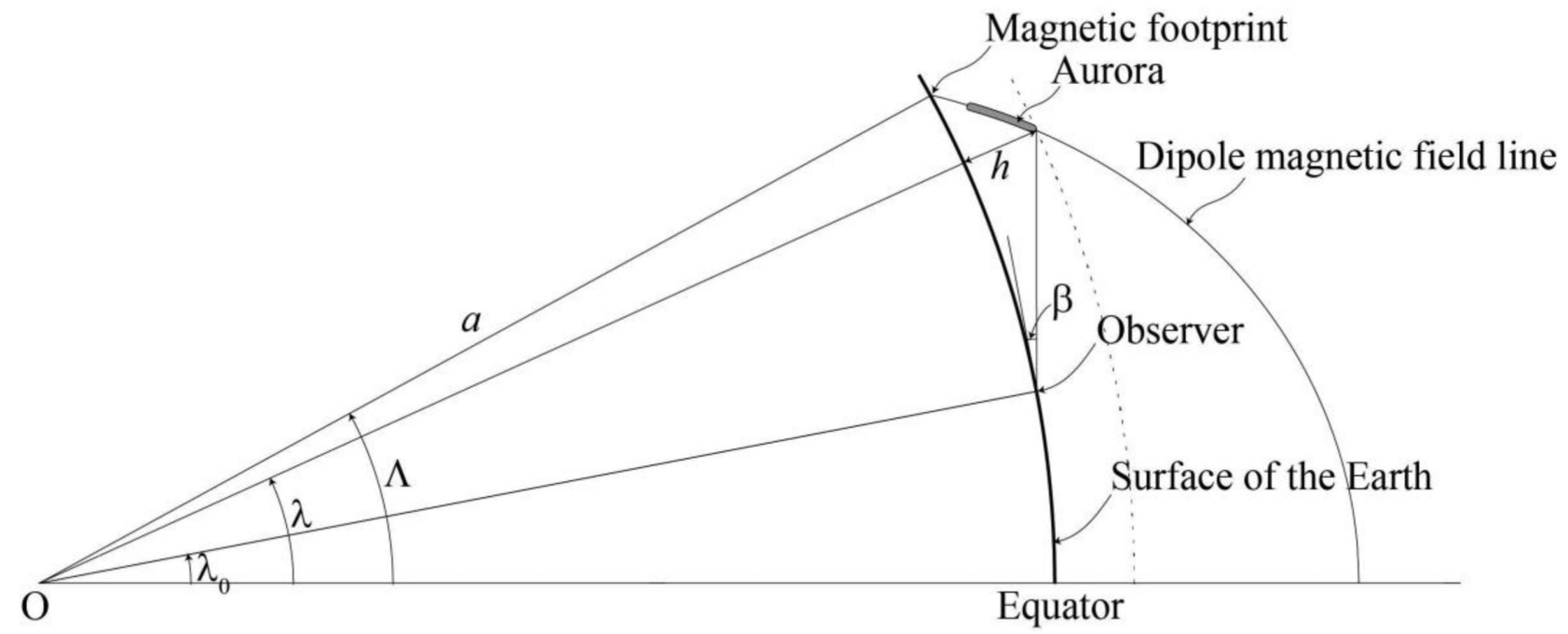

Figure 2. The relationship between the elevation angle of the auroral display $(\beta)$, and the invariant latitude (ILAT) of the aurora $\Lambda$ in dipole geometry (Hayakawa et al. 2018b).

the horizon' (J2-8; 23.2 $2^{\circ}$ MLAT). Therefore, we compute its equatorward boundary of auroral oval as $31.6^{\circ}$ ILAT, assuming the height of visible auroral as $400 \mathrm{~km}$. This is roughly consistent with a report from Okushiri $\left(\mathrm{J} 3-7\right.$ : N42 ${ }^{\circ} 10^{\prime}, \mathrm{E} 139^{\circ} 31^{\prime} ; 31.9^{\circ}$ MLAT) and Futoro (J3-8: N42 $23^{\prime}$, E $139^{\circ} 49^{\prime} ; 32.2^{\circ}$ MLAT). Here, the observer stated the elevation angles as 'more than $80^{\circ}$ above the horizon' and ' $85^{\circ}$ above the horizon', respectively. We compute the equatorward boundary of the auroral oval as $35.1^{\circ}$ ILAT for these cases. If we expect the maximum altitude of the aurora to be $800 \mathrm{~km}$ (following Loomis 1861), the equatorward boundaries of auroral oval are computed to be $37.7^{\circ}$ ILAT, $37.5^{\circ}$ ILAT, and $38.0^{\circ}$ ILAT, for Matsuyama, Futoro, and Okushiri, respectively. Note that variations in the calculated low-latitude boundaries of the auroral display for the various sites can be due to timing differences of elevation reports (see Table 1 for their durations of visibility) as well as uncertainties in the reported angles.

\subsection{Observations from South Africa and Australia}

In South Africa, aurorae australis were visible throughout the Cape Colony down to Carnarvon Farm (S31 ${ }^{\circ} 34^{\prime}$, E026 $44^{\prime}$; - $32.0^{\circ}$ MLAT). Hopkinson (1909, p.69) states 'The Secretary of the Cape Meteorological Commission records that a manifestation of what was supposed to be the Aurora Australis was reported from Carnarvon Farm on the night of the 25 September, being particularly brilliant from 9.30 to 11 p.m. [19:30-21:00 UT]'. The report by
Eddie (1909, pp. 40-41) provides further detail with its elevation angle at Grahamstown $\left(\mathrm{S}_{3} 3^{\circ} 19^{\prime} \mathrm{E} 026^{\circ} 31^{\prime} ;-33.6^{\circ} \mathrm{MLAT}\right)$. Here the aurorae australis, 'notwithstanding the bright moonlight, manifested itself as a lovely rose-pink blush overspreading the sky' and 'The auroral flush, which was greatly intensified on the southern horizon, extended up to and beyond the zenith in the eastern and southern portions' with significant motions and pulsations. Considering the aurorae australis extended equatorward beyond the zenith at Grahamstown $\left(-33.6^{\circ}\right.$ MLAT), it is calculated that the equatorward boundary of the auroral oval in the South African sector was at least beyond $36.1^{\circ}$ ILAT or $38.3^{\circ}$ ILAT, estimating auroral elevation as 400 or $800 \mathrm{~km}$, respectively. Chapman (1957c) reported that the aurorae were observed farther equatorward from Durban $\left(\mathrm{S} 29^{\circ} 51^{\prime}, \mathrm{E} 031^{\circ} 01^{\prime} ;-31.1^{\circ} \mathrm{MLAT}\right)$ but this record includes those of Singapore and other stations in a secondary source that has been disputed by Silverman (1995). These questionable observation sites will be discussed further in Section 3.3.

In Australia, aurorae australis were visible in several cities including Dalby $\left(\mathrm{S} 27^{\circ} 11^{\prime}, \mathrm{E} 151^{\circ} 16^{\prime} ;-35.6^{\circ} \mathrm{MLAT}\right)$, which is more equatorward than Brisbane $\left(\mathrm{S} 27^{\circ} 28^{\prime}, \mathrm{E} 153^{\circ} 01^{\prime}\right.$; $-35.7^{\circ}$ MLAT) (The Brisbane Courier, 1909-09-27, p.4). Silverman (1995) considered the latter, Brisbane, to be the most equatorward observational site in Australia. Another report from Warwick (S28 $13^{\prime}$, $\mathrm{E} 152^{\circ} 02^{\prime}$; $\left.-36.6^{\circ} \mathrm{MLAT}\right)$ states 'On Saturday evening last, between the hours of 10 [12 UT] and 12 [14 UT], a unique manifestation of the phenomenon known in the Southern Hemisphere as the Aurora 
Australis, was visible in Warwick. The spectacle was seen as a beautiful pale, opalescent glow in the south, travelling over an area of the heavens, while bright ribbons ran up nearly to the zenith. The rays rose perpendicularly from an apparently dark arch, and the luminosity played over the arch'. The rays were not stationary, but appeared and disappeared, mounting upwards to a great height, and slowly moving eastward and westward. This was followed, at about mid night, by a red glow, so bright that many people thought it was a fire' (Warwick Examiner and Times, 1909-09-27, p. 8). As aurorae australis extended up 'nearly to the zenith' at Warwick $\left(-36.6^{\circ}\right.$ MLAT), it appears that the auroral oval extended at least down to $38.9^{\circ}$ ILAT or $40.8^{\circ}$ ILAT, estimating auroral elevation as 400 or $800 \mathrm{~km}$, respectively. Considering its observational timing (22:0024:00 LT; 12:00-14:00 UT), this observation corresponds with the beginning of the magnetic storm as described below. Another report from more poleward observational sites in Australia such as Sydney $\left(\mathrm{S} 33^{\circ} 52^{\prime}, \mathrm{E} 151^{\circ} 12^{\prime} ;-42.2^{\circ} \mathrm{MLAT}\right)$ shows that the aurorae extended even more equatorward. A newspaper in Sydney tells us 'the red glow extended over very nearly the whole sky, only a small area due north being unaffected' (Brown 1909, p.97). Assuming $20^{\circ}$ in the north sky is left, the equatorward boundary of auroral oval is estimated to be $36.8^{\circ}$ ILAT $\left(-34.4^{\circ}\right.$ MLAT) or $34.3^{\circ}$ ILAT $\left(-28.8^{\circ}\right.$ MLAT), based on a peak auroral elevations of 400 and $800 \mathrm{~km}$, respectively.

These reconstructions of equatorward boundary of auroral oval in the South African sector ( $36.1^{\circ}$ ILAT or $38.3^{\circ}$ ILAT) and in the Australian sector ( $36.8^{\circ}$ ILAT or $34.3^{\circ}$ ILAT) are roughly encompassed by those of the two reconstructions in the Japanese sector $\left(31.6^{\circ}\right.$ ILAT or $37.7^{\circ}$ ILAT and $35.1^{\circ}$ ILAT or $37.5^{\circ}$ ILAT), These differences might be attributed to the different stage of the magnetic storm, which we clarify in upcoming sections.

\subsection{Observations from Singapore, Batavia (Jakarta), Rodriquez (Mauritius), Durban, and the Cocos (Keeling) Islands}

The auroral display may have been visible even farther equatorward. Chapman (1957a) states that the aurorae were observed at Singapore, Batavia, the Cocos (or Keeling) Islands, and elsewhere. Silverman (1995) revealed that all of these reports are based on an article in the The West Australian (1909-09-27, p.7) newspaper attributing possibly telegraph-related 'phenomena' to 'the aurora'. Philologically, the Nature (v.81, p.524) report cited in Chapman (1957a) is hearsay of hearsay and is of questionable reliability, as pointed out by Silverman (1995).

The original newspaper article in The West Australian (190909-27, p.7) reads as follows: 'Telegrams from the country, and from the Eastern States show that the aurorae were observed in all its richness throughout Australia, whilst cable advices received by the Eastern Extension Company state that not only was the phenomenon witnessed at Cocos Island, Batavia, Singapore, Rodriquez [Mauritius], and Durban, but the company's lines were affected by very strong and troublesome terrestrial currents due to magnetic influences', while Nature (v.81, p.524) reports 'Mr W. E. Cooke, Government astronomer, Western Australia, informs us that the most magnificent aurora visible in Australia for half a century occurred on 25 September. From reports in the West Australian, it appears that the aurora was observed throughout Australia, as well as at Cocos Island, Batavia, Singapore, Rodriquez, Durban, and elsewhere....'.

We use triangulation to evaluate the possibility that aurorae are indeed visible from the observational sites listed in The Western
Australia in the maximum phase of auroral display as witnessed in Japan. The geographical coordinates of these sites are: Cocos Islands $\left(\mathrm{S} 12^{\circ} 07^{\prime}, \mathrm{E}^{\circ} 6^{\circ} 54^{\prime}\right)$, Batavia $\left(\mathrm{S}^{\circ} 6^{\circ} 08^{\prime}, \mathrm{E} 106^{\circ} 49^{\prime}\right)$, Singapore (N01 ${ }^{\circ} 20^{\prime}$, E103 $\left.50^{\prime}\right)$, Rodriquez (S19 $41^{\prime}$, E063 ${ }^{\circ} 25^{\prime}$ ), and Durban $\left(\mathrm{S} 29^{\circ} 51^{\prime}, \mathrm{E} 031^{\circ} 01^{\prime}\right)$. Considering the location of contemporary geomagnetic north pole determined by IGRF12 (Thébault et al. 2015), their MLATs are $-23.2^{\circ}$ at Cocos Islands, $-17.5^{\circ}$ at Batavia, $-10.0^{\circ}$ at Singapore, $-27.1^{\circ}$ at Rodriquez, and $-31.1^{\circ}$ at Durban.

Singapore is the most equatorward observational site in terms of MLAT $\left(-10.0^{\circ}\right.$ MLAT). Here, we make two assumptions. First, the equatorward boundary of the auroral oval in the Japanese meridian ( $31.6^{\circ}$ ILAT or $37.7^{\circ}$ ILAT) is the same as that in the meridian of Singapore. Secondly, the auroral oval is symmetric about the magnetic equator. In this case, the expected elevation angle of the auroral display at Singapore would be $1.2^{\circ}$ with the altitude of $400 \mathrm{~km}$ and $5.3^{\circ}$ with the altitude of $800 \mathrm{~km}$. Atmospheric refraction could make it appear at a higher elevation angle. Thus, on the calculation, one cannot rule out the possibility that aurorae were seen from Singapore. The visibility at other observational sites is more probable. For Batavia, the observational site with the second lowest MLAT $\left(-17.5^{\circ}\right)$, we compute an expected elevation angle as $12^{\circ}$ with the altitude of $400 \mathrm{~km}$ and $26^{\circ}$ with the altitude of $800 \mathrm{~km}$.

Therefore, we consider auroral displays might have been seen in these observational sites at low elevation angles, assuming the same equatorward boundary $\left(31.6^{\circ}\right.$ ILAT or $37.7^{\circ}$ ILAT at $16: 40$ 16:57 UT) as in the Japanese sector. Nevertheless, we need to note that the two source documents currently available in the scientific community are secondary records based on the hearsay as shown in Silverman (1995). We note that all of the listed stations, Cocos Islands, Batavia, Singapore, Rodriquez, and Durban, correspond to the nodes on the Eastern Extension Company's submarine cable route (Fig. 3). We cannot rule out the possibility that aurorae were observed at any of these sites, but we do permit the possibility that the reports of aurorae in each case were based on a conflation of aurorae with telegraph disturbance experienced at that location. Therefore, further surveys for auroral reports for these observational sites with lowest MLAT are needed to affirm these sources. We also note that actual observations of aurorae at the Cocos Islands $\left(-23.2^{\circ}\right.$ MLAT), Rodriquez (-27.1 ${ }^{\circ}$ MLAT), and Durban ( $-31.1^{\circ}$ MLAT) would be compatible with the lowest latitude observations from Japan and South Africa.

\section{COMPARISON BETWEEN MAGNETIC AND AURORAL DISTURBANCES}

\subsection{Magnetometer observations for 1909}

Fig. 4(a) shows the traces of the H-component disturbances acquired at the four stations (San Fernando, Spain (N36 $28^{\prime}$, W006 ${ }^{\circ} 12^{\prime} ; 41.0^{\circ}$ MLAT; Azcárate 1910); Vieques, Puerto Rico (N18 09’, W065 27’; 29.5 MLAT; Hazard 1912), Apia, Western Samoa (S1349', W171 $47^{\prime}$; $-16.1^{\circ}$ MLAT; Wegener 1914 ), and Mauritius (S20 $05^{\prime}$, E057 $33^{\prime} ;-26.5^{\circ}$ MLAT; Claxton \& Walter 1913), together with the Dst index (red line) constructed by Love, Hayakawa \& Cliver (2019). Love, Hayakawa \& Cliver (2019), calculated a minimum Dst value of $-595 \mathrm{nT}$ for this event.

As noted by Love, Hayakawa \& Cliver (2019), the H-component magnetograms exhibit a marked asymmetry during the first $\sim 1.5 \mathrm{~h}$ following the sudden commencement at $\sim 11: 40$ UT, with San Fernando and Vieques exhibiting a strong negative excursion during this interval and Apia showing a strong positive pulse, while the 


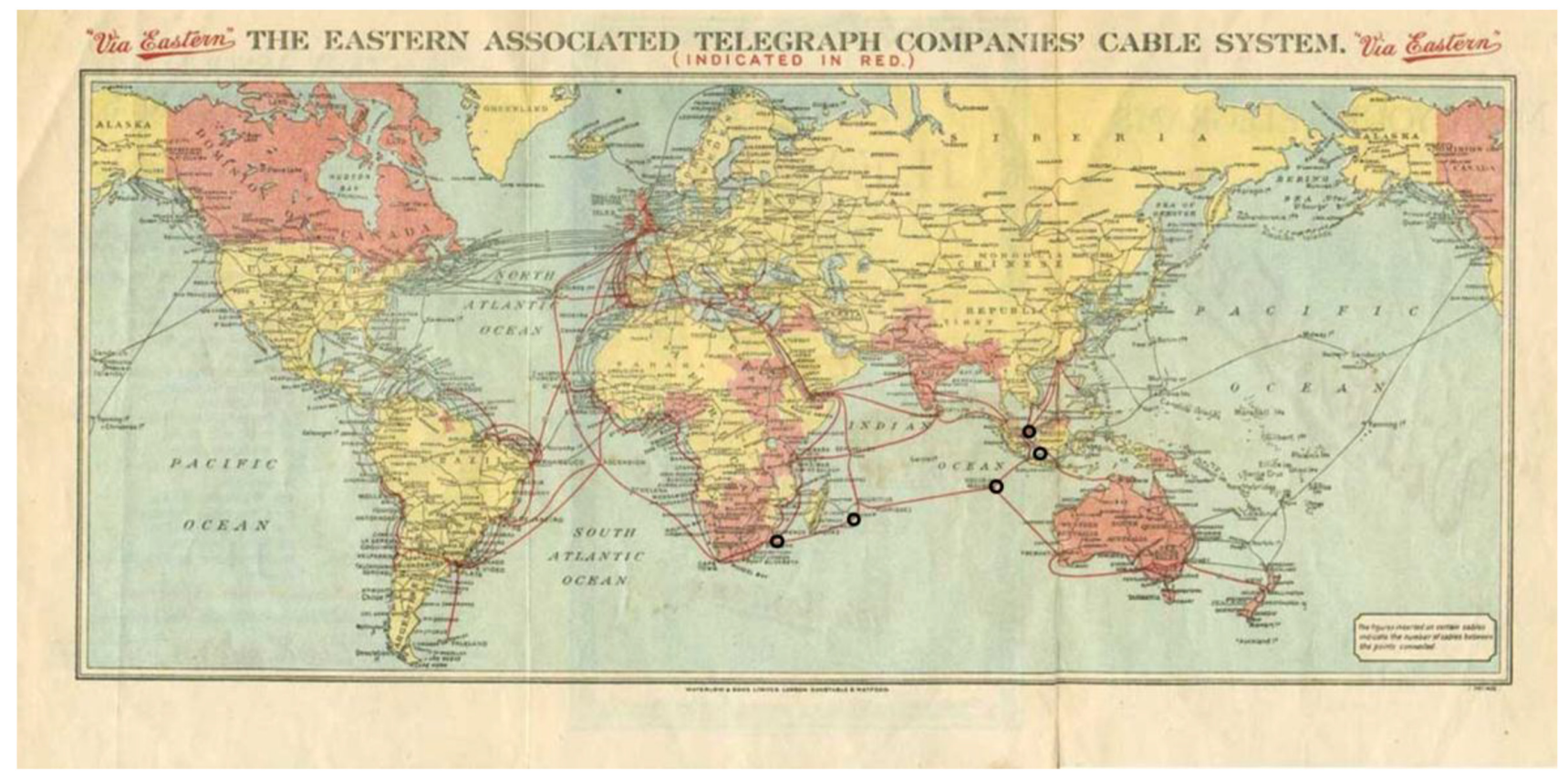

Figure 3. The Eastern Associated Telegraph Companies' cable system in 1902. The observational sites of the 'aurora' in Nature (v.81, p.524) and 'phenomena' in The West Australian are located along these telegraph lines, as enhanced by the black circles. This figure is available at: http://atlantic-cable.com/CableCos/ CandW/EATC/index.htm.
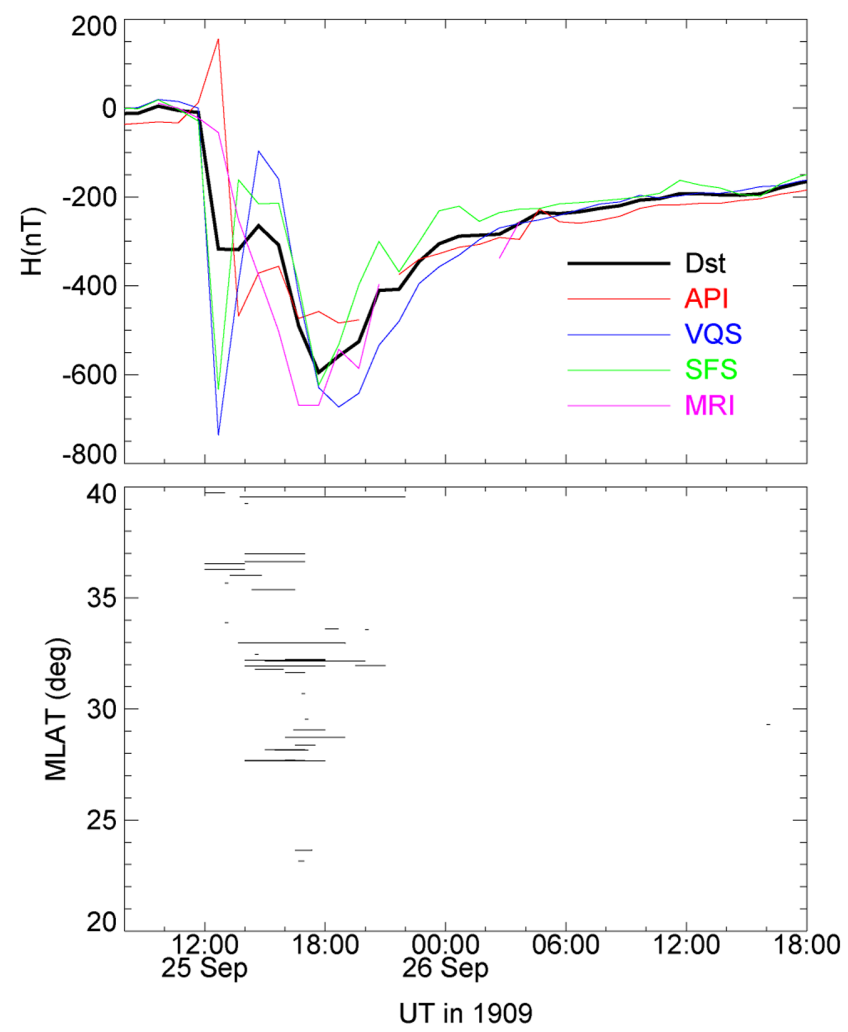

Figure 4. (a, above) H-component of magnetic disturbance at four stations at low- and mid-latitudes (San Fernando, SFS; Vieques, VQS; Apia, API; Mauritius, MRI) together with estimated Dst value (from Love, Hayakawa, \& Cliver 2019), and (b, below) duration of auroral visibility as a function of the absolute value of MLAT and UT. Only the sites located within $\pm 40^{\circ}$ MLAT are shown. Their timing is converted to the universal time (UT).
Mauritius trace was relatively flat before dropping sharply. Love, Hayakawa \& Cliver (2019) interpreted this early behaviour in storm evolution in terms of the effect of substorm-related currents on the relatively low-latitude magnetograms. The early $\mathrm{H}$-variation at Tokyo (N35 $41^{\prime}$, E139 $46^{\prime} ; 25.5^{\circ}$ MLAT) shown in Fig. 5 is similar to that at Apia (strong positive pulse), while the variation at Alibag (N18 $39^{\prime}$, E072 $52^{\prime} ; 96^{\circ}$ MLAT) shows similarities to that at Mauritius, with an early muted response (though in the opposite direction from that at Mauritius) followed by a strong rapid negative excursion.

\subsection{Relative timing of magnetic disturbance and aurora}

\subsubsection{September 1909}

Fig. 4(b) shows the duration of the auroral observations below $\pm 40^{\circ}$ MLAT, namely in Japan, South Africa, and northern Australia. Aurorae were well-observed from Perth, Australia as well. Note that the reports of the aurorae start to appear at $\sim 12 \mathrm{UT}$, and end by $\sim 18$ UT. This duration corresponds to the storm main phase and the early recovery phase as identified by the reconstructed Dst index shown in Fig. 4(a). The equatorward most observation was made near the Dst minimum.

Quoting from The West Australian newspaper, 'Towards 9 o' clock [13 UT] the sky from east to west in a southern sweep was observed to be suffused with a strange white glow. To the north the sky was clear and cloudless, but within the half-circle of the strange influence weird luminous clouds appeared to rise from nowhere, to ascend towards the zenith and vanish. The heavens seemed afire. Yet it was a fire supernaturally regulated into a bewildering succession of arches, through which a multiplicity of columns of white light rose almost perpendicularly, converging very gradually to the horizon. At one time, the whole empyrean seemed vanishing in a celestial fire, [soon] greenish clouds rose as from a house burning in the heavens, and then there came a suffusion of pink deepening into carmine, 

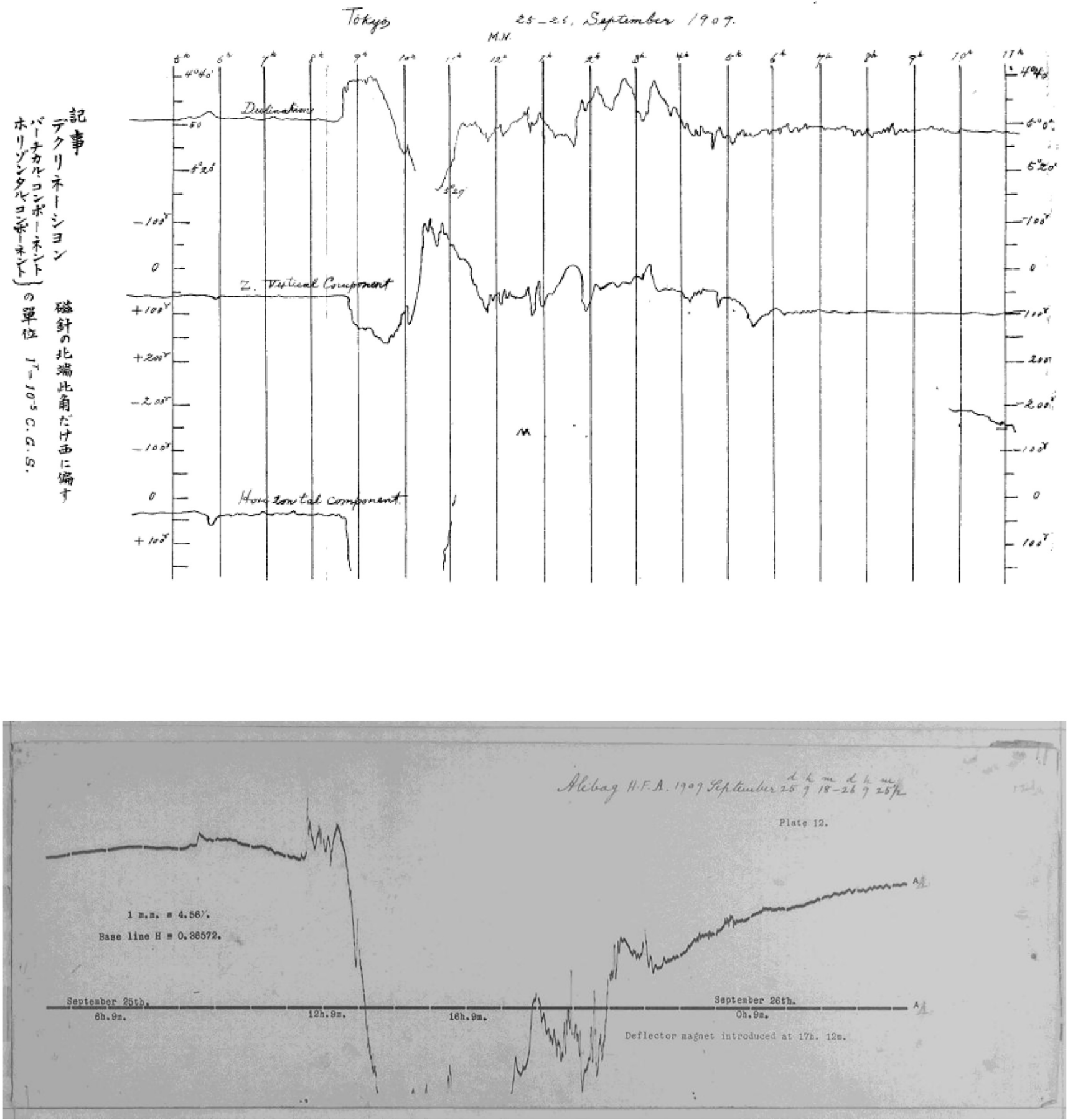

Figure 5. Magnetic records at Tokyo (TOK; top) and Alibag (ABG; bottom). The former shows declination, vertical and horizontal components, reproduced from Uchida (1909). The geomagnetic field data at Alibag used in this paper was obtained in Alibag, and provided by the WDC for Geomagnetism, Kyoto (http://wdc.kugi.kyoto-u.ac.jp/wdc/Sec3.html). Note that the polarities of the magnetic record at Tokyo are opposite (positive downward).

till the sky was a restless sea of blood-red fire.... The beauty of the display fluctuated throughout the evening. Towards 10 o'clock [14 UT] it was on the wane, and many who had spent a full hour watching the phenomenon thought that the great transformation scene was closing. But as midnight [16 h UT] approached the glow became more brilliant, and glorious lights of all colours danced across the trembling sky. Even at this late hour thousands were feasting their eyes on the dazzling spectacle, but as again the quivering sky seemed to be losing the richness and brilliancy of its colouring, they retired to their beds. It is related, however, that once more in the early morning the aurorae developed in all its magnificence. After that its splendours slowly faded away, not to reappear for perhaps another $10 \mathrm{yr}$. Throughout the metropolitan area the visitation created profound excitement as well as a good deal of mystery. The heavens were more intently studied for those 2 or $3 \mathrm{~h}$ on Saturday night than they had been ever before'. Thus 
the early auroral behaviour in Perth $\left(\mathrm{S} 31^{\circ} 57^{\prime}, \mathrm{E} 115^{\circ} 52^{\prime} ;-43.3^{\circ}\right.$ MLAT) closely tracked the first sharp dip and recovery in the magnetogram from Vieques $\left(\mathrm{N} 18^{\circ} 09^{\prime}\right.$, W65 $27^{\prime} ; 29.5^{\circ}$ MLAT), which is nearly antipodal geographically. The subsequent auroral activity at Perth appears to be more closely related to ring current evolution.

\subsubsection{March 1989}

Fig. 6 shows that the Dst variation during the March 1989 storm (minimum Dst of $-589 \mathrm{nT}$ ) was comparable to that of the storm in September 1909 (estimated Dst of -595 nT; Love, Hayakawa \& Cliver 2019). For the 1989 event, the low-latitude aurorae were reported from the Cayman Islands (30.4 ${ }^{\circ}$ MLAT), Cancun, Mexico (31.9 $9^{\circ}$ MLAT), Exmouth, Australia ( $-33.3^{\circ}$ MLAT), and from the ships Eland $\left(-29.0^{\circ}\right.$ MLAT), Sentis (-29.5 MLAT), and London Spirit (30.7 ${ }^{\circ}$ MLAT) (Silverman 2006a). The auroral electron precipitation observed by the U. S. Defense Meteorology Satellite Program extended, at least, down to $40.1^{\circ}$ MLAT (Rich \& Denig 1992), which is consistent with the ground-based reports, near the time of the Dst minimum (see also Yokoyama et al. 1998). The Akebono satellite observed the enhancement of the magnetospheric convection electric field (Shinbori et al. 2005). The peak amplitude of the electric field of $46 \mathrm{mV} / \mathrm{m}$ was recorded at $L=2.3-3.3$ near the plasmapause. The strong convection electric field may be responsible for the earthward transport of the magnetospheric ions and electrons. The earthward transport of the magnetospheric ions results in the enhancement of the ring current as manifested by the Dst index (e.g. Ebihara \& Ejiri 2000), and the earthward transport of the magnetospheric electrons (originating from the plasma sheet and the plasmasphere) results in the equatorward displacement of the auroral region (e.g. Ebihara et al. 2017). The UV imager onboard the Dynamics Explorer (DE-1) satellite captured the aurorae (Allen et al. 1989; Pulkinnen et al. 2012). On the basis of the auroral image captured at 0151 UT on 14 March 1989 (just after the Dst minimum), Allen et al. (1989) concluded that the auroral region extended to Alabama, Georgia, and northern Florida and over Texas, Oklahoma, and New Mexico. No details are given on the timing or elevation angles of these observations, and further work will be required to compare satellite observations and ground-based determinations of the equatorward boundary of the overhead auroral oval in this unique extreme storm for which both types of data are available.

\subsection{Telegraph disturbance}

According to Uchida (1909, p.702) operators in the telegraph station at Tokyo $\left(\mathrm{N} 35^{\circ} 41^{\prime}, \mathrm{E} 139^{\circ} 46^{\prime} ; 25.5^{\circ}\right.$ MLAT) recorded geomagnetically induced currents (GICs) at 22:35 LT (13:35 UT) in long-distance telegraph lines. Their communication with the Ogasawara station $\left(\mathrm{N} 27^{\circ} 06^{\prime}, \mathrm{E} 142^{\circ} 11^{\prime} ; 17.2^{\circ}\right.$ MLAT) upon the telegraph line between Tokyo and Guam was also disturbed. They first suspected local breakdowns and contacted the station at Guam $\left(\mathrm{N} 13^{\circ} 35^{\prime}, \mathrm{E} 144^{\circ} 52^{\prime} ; 4.0^{\circ}\right.$ MLAT) for this telegraph disturbance and confirmed disturbances with strong voltage on the submarine telegraph cable lines around Guam. Indeed, Uchida (1909, p.710) records the voltage between Tokyo and Yokkaichi as $>110$ at 22:35 LT (13:35 UT). This voltage decreased to $>70$ at 22:42 LT (13:42 UT) and finally to $\approx 14$ at 23:20 LT (14:20 UT). They found another disturbance upon the Tokyo-Guam line from 25:40-26:20 LT (16:40-17:20 UT), while this disturbance did not affect telegraph communications due to few communications during midnight. This report shows that such a major solar disturbance can affect social infrastructures at low MLATs.

According to the Dst index reconstructed by Love, Hayakawa \& Cliver (2019), the interval of the telegraphic glitches taking place between $\sim 13: 35$ UT and $\sim 17: 20$ UT corresponds to the storm main phase (Dst $\sim-320 \mathrm{nT}$ to $\sim-570 \mathrm{nT}$ ). This interval also corresponds to that of the low-latitude aurorae witnessed at many points at $< \pm 40^{\circ}$ MLAT. A large-amplitude of the GIC is induced by magnetospheric and/or ionospheric current system. One possible cause of the telegraphic disturbance is the storm-time ring current that developed between $\sim 11: 40$ UT and $\sim 17: 40$ UT. Kappenman (2004) has shown that the magnitude of GICs flowing in the Japanese power grid increases with the magnitude of the Dst index. Another possible cause is the substorm-current wedge system that consists of field-aligned current and the tail current (McPherron, Russell \& Aubry 1973). Downward field-aligned current is connected to the dawnside ionosphere, and upward field-aligned current is connected to the duskside ionosphere. The pair of field-aligned currents causes magnetic disturbances at mid- and low- latitudes (Pytte, Mcpherron \& Kokubun 1976). The magnetic disturbance recorded at Tokyo (Fig. 5) shows a decrease in the H-component and a positive excursion of the D-component during the interval of $\sim 22-23$ LT ( 13-14 UT). It is probable that Tokyo would be located at southwest of the upward field-aligned current during this interval. The D-component variation shows a few negative excursions during $\sim 25: 40-30: 00$ LT ( 16:40-21:00 UT). Although the disturbance of the H-component is unavailable during this interval, it can be speculated that Tokyo was located at southeast of the downward field-aligned current. In addition to the development of the ring current, the formation of the substorm current wedge may also cause the telegraphic disruption. By considering the above discussion, at mid-latitude, we suggest that there are two regions where GICs can be caused by field-aligned currents. One is southwest of the upward field-aligned current, and the other is southeast of the downward field-aligned current. In these regions, the H-component of the magnetic field is expected to decrease significantly because of the combination of the effects of the ring current and the current wedge. Tokyo was probably situated in such hazardous regions during the 25 September 1909 storm.

\section{SOLAR ACTIVITY ASSOCIATED WITH THE 25 SEPTEMBER 1909 MAGNETIC STORM}

\subsection{Solar flare observations}

Astronomers recorded a major 'solar disturbance' on 24 September 1909 that was linked to the great storm on 25 September. Lockyer (1909) made a series of solar photographs with his spectroheliograph on 17-18, 20-22, and 24 September.

On 24 September, he observed significant intensity enhancements in a sunspot group with approximate latitude $5^{\circ} \mathrm{S}$ and Carrington longitude $305^{\circ}$. This group had its central meridian passage, the optimum time for a solar eruption to produce a geomagnetic storm, on 23 September at $\sim 19$ GMT (Jones 1955). At the time of the SFE ( $\sim 12$ GMT on 24 September) the group would have been located at $\sim 10 \mathrm{~W}$ (Newton 1943). Lockyer (1909) obtained Ca II K heliograms at 10:06, 10:11, 11:11, and 11:16 in GMT on 24 September that are reproduced in Fig. 7 along with images taken at 12:12 GMT on 21 September and 10:42 GMT on 22 September for comparison. Lockyer, who had routinely monitored the Sun in Ca II K line at the South Kensington Solar Physics Observatory since July 1903, described the 'tremendous activity' in the spot group near central 


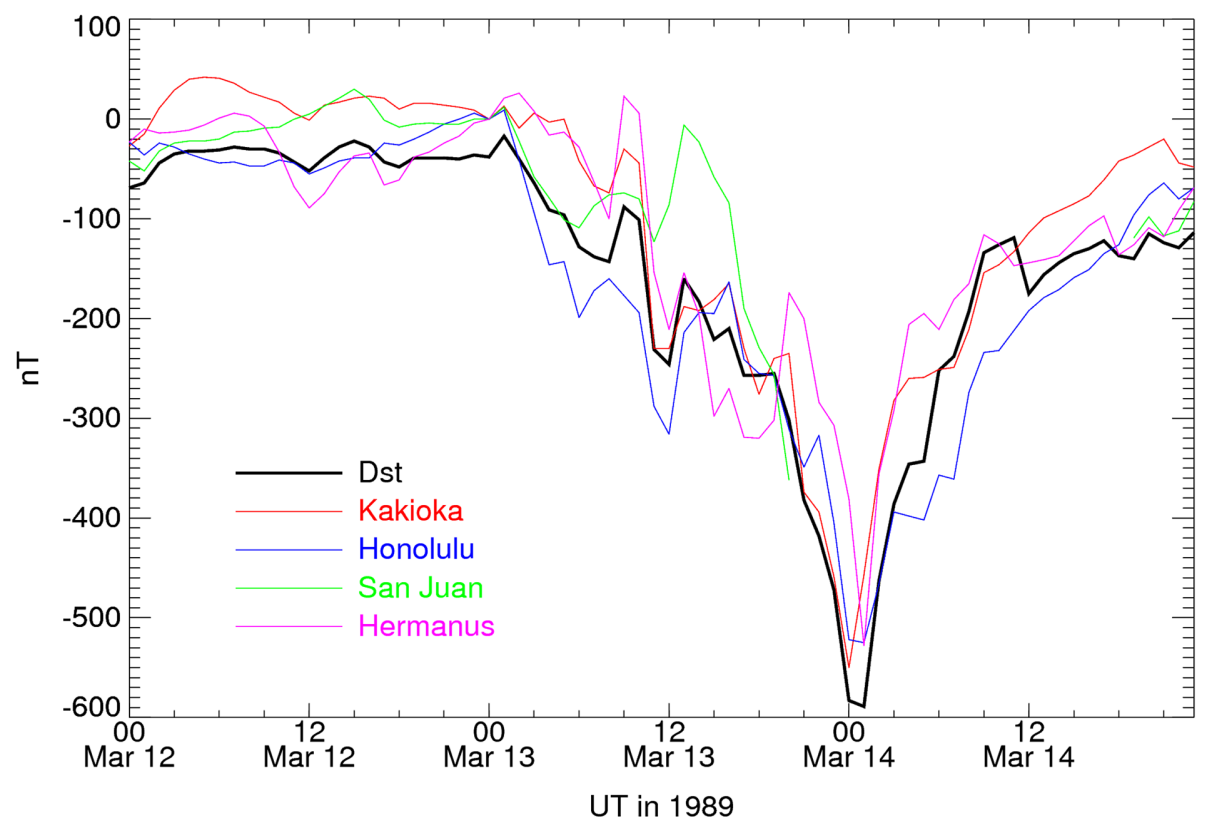

Figure 6. Dst value of the magnetic storm on 13/14 March 1989, based on the value of H-component of the four Dst stations.The geomagnetic field data used in this paper was obtained in Kakioka, Honolulu, Hermanus, San Juan, and Hermanus, and provided by the WDC for Geomagnetism, Kyoto (http://wdc.kugi.kyoto-u.ac.jp/wdc/Sec3.html). See the Dst value World Data Center for Geomagnetism, Kyoto et al. (2015).

meridian at $\sim 10$ GMT on 24 September - what we would term a flare or eruptive flare today (Cliver 1995) — as being 'quite unique in the records made with the spectroheliograph of this observatory'.

Lockyer (1909) first noticed the disturbance on 24 September at 10:06 GMT and noted 'The two most striking features are the great increase in intensity, and the nearly complete change of form'. The images in panels (c) and (d) in Fig. 7 from 24 September show a 'complete transformation' from those in (a) and (b) taken on the 22 September due to an 'overhanging calcium cloud' (flare ribbon today) that nearly 'obliterated' the 'two dark more or less elliptical spots'. About $1 \mathrm{~h}$ later, at 11:11 GMT (panel e), 'The intensity of the whole group is very considerably reduced ...', while at 11:16 GMT (panel f), 'changes are still going on, but nothing so violent as those which occurred previously'.

Other astronomers witnessed the eruption on 24 September. Frederick Slocum was monitoring the Sun with the Rumford spectroheliograph with Ca II H line. Slocum (1910, pp. 27-28) witnessed 'The high-level calcium flocculi over the spot present a marked spiral form, with several brilliant eruptions on the branches and outside the spiral' on 10:26:07 GMT. Edwin Holmes saw the solar disc in $\mathrm{H} \alpha$ (Fraunhofer $\mathrm{C}$ line; the line used for modern flare patrols) roughly $1 \mathrm{~h}$ later, around 11:30 GMT. He states 'I made an attempt to see prominences, but getting the sunspot on the slit I saw at once that when the spot-shade crossed the $\mathrm{C}$ line it was not dark but brilliant, far more brilliant than the general surface of the Sun there, for I was able to see it as a considerable-sized luminosity over both members of the spot with slit open to a large extent. The time was 11.30 a.m., and about an hour afterwards the brilliancy faded somewhat' (Holmes 1909, p.396). Fowler (1909, p.396) of South Kensington made an observation at 12:20 GMT and reported about 'a brilliant reversal of the $\mathrm{C}$ line of hydrogen over one of the umbræ' and related this with a 'very bright overlying prominence'. Lockyer (1909) tentatively linked the solar disturbance near $\sim 10$ GMT with the magnetic storm on the 25 September. Newton (1943) used this flare-storm association in the first statistical, rather than anecdotal, study linking solar flares to geomagnetic storms.

The flare was accompanied by a geomagnetic crochet observed at Greenwich with an H-component amplitude of $\sim-40 \mathrm{nT}$ from $\sim 11-12.5$ GMT (cf. Jones 1955, p.80) that can be seen in Fig. 1 from Love, Hayakawa \& Cliver (2019). The time profile of the SFE suggests that the intense brightening Holmes observed in $\mathrm{H} \alpha$ at $\sim 11: 30$ GMT represented the most energetic component of the flare activity Lockyer first observed at $\sim 10 \mathrm{GMT}$. This coincidence also gives timing closer to the 1859 event $(\sim 11.1-12$ GMT; see Cliver \& Svalgaard 2004) facilitating comparison of the Greenwich SFE amplitudes of the 1909 and 1859 events for determination of SXR flare size (Cliver \& Svalgaard 2004; Clarke et al. 2010; Cliver \& Dietrich 2013).

\subsection{Sunspot observations}

Fig. 8 shows the whole-disc sunspot drawings between 23 and 25 September 1909, obtained from the Kalocsa Observatory (N46 $32^{\prime}$, E018 59') in Hungary digitized by Baranyi, Györi \& Ludmány (2016). The large sunspot group near the disc centre, designated Greenwich No. 6728 (Jones 1955), in which the flare activity after 10 GMT on 24 September originated had a mean-corrected whole spot area of 619 millionths of a solar hemisphere $(\mathrm{msh})$ with a value of $631 \mathrm{msh}$ on 24 September and a maximum whole spot area of 908 msh on 28 September.

The heliograms and descriptions in time show that the first flare occurred on the above right (northwestern) side of the sunspot group. We cannot determine the magnetic structure of the solar active region since we do not have magnetic measurements. However, this region is likely classified as a delta-type spot, which is the most flare-productive spot category (Künzel 1960) as two umbrae 

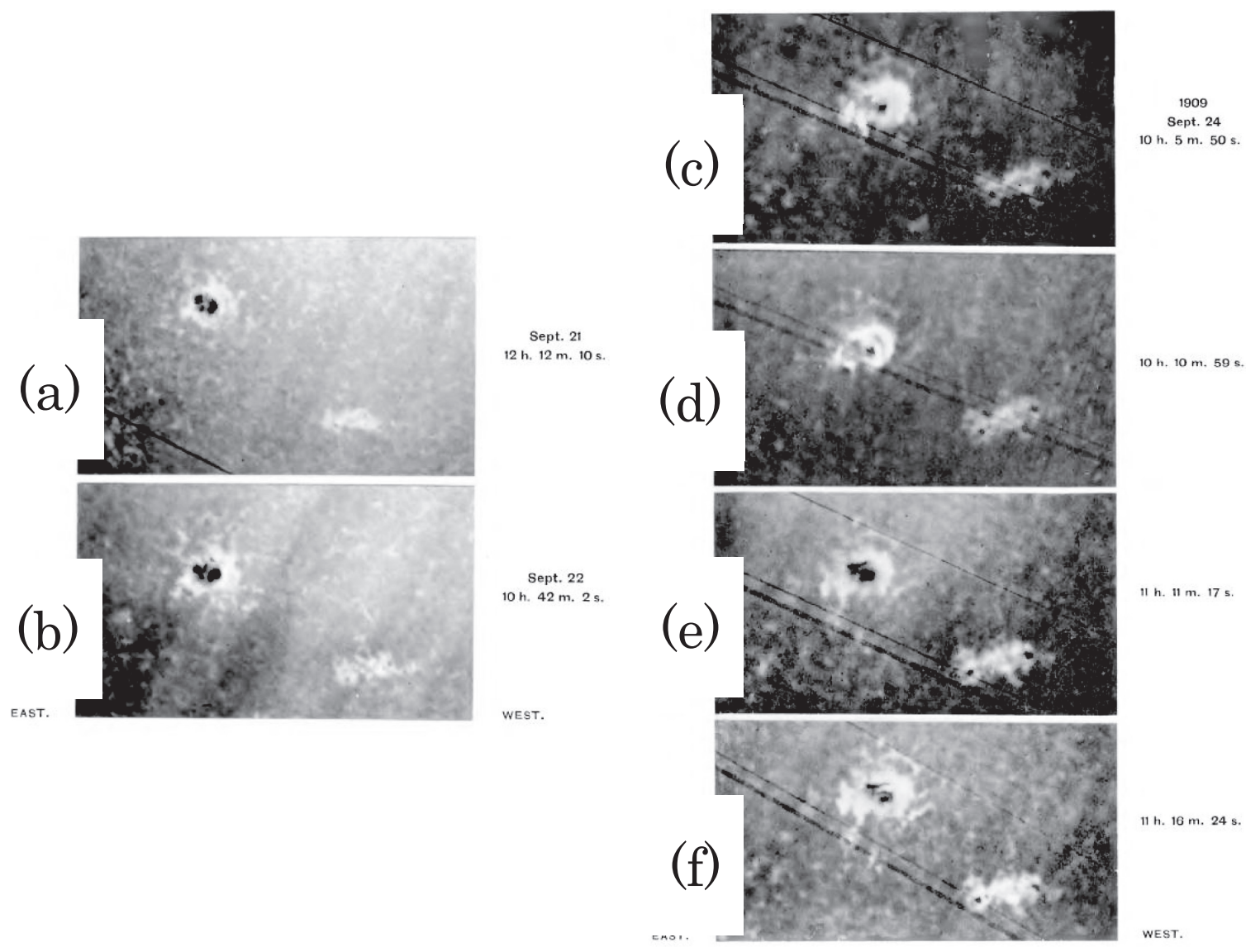

Figure 7. Lockyer's heliograms from 21 September ( $12 \mathrm{~h} 12 \mathrm{~m} 10 \mathrm{~s})$ to 24 September ( $11 \mathrm{~h} 10 \mathrm{~m} 24 \mathrm{~s})$.

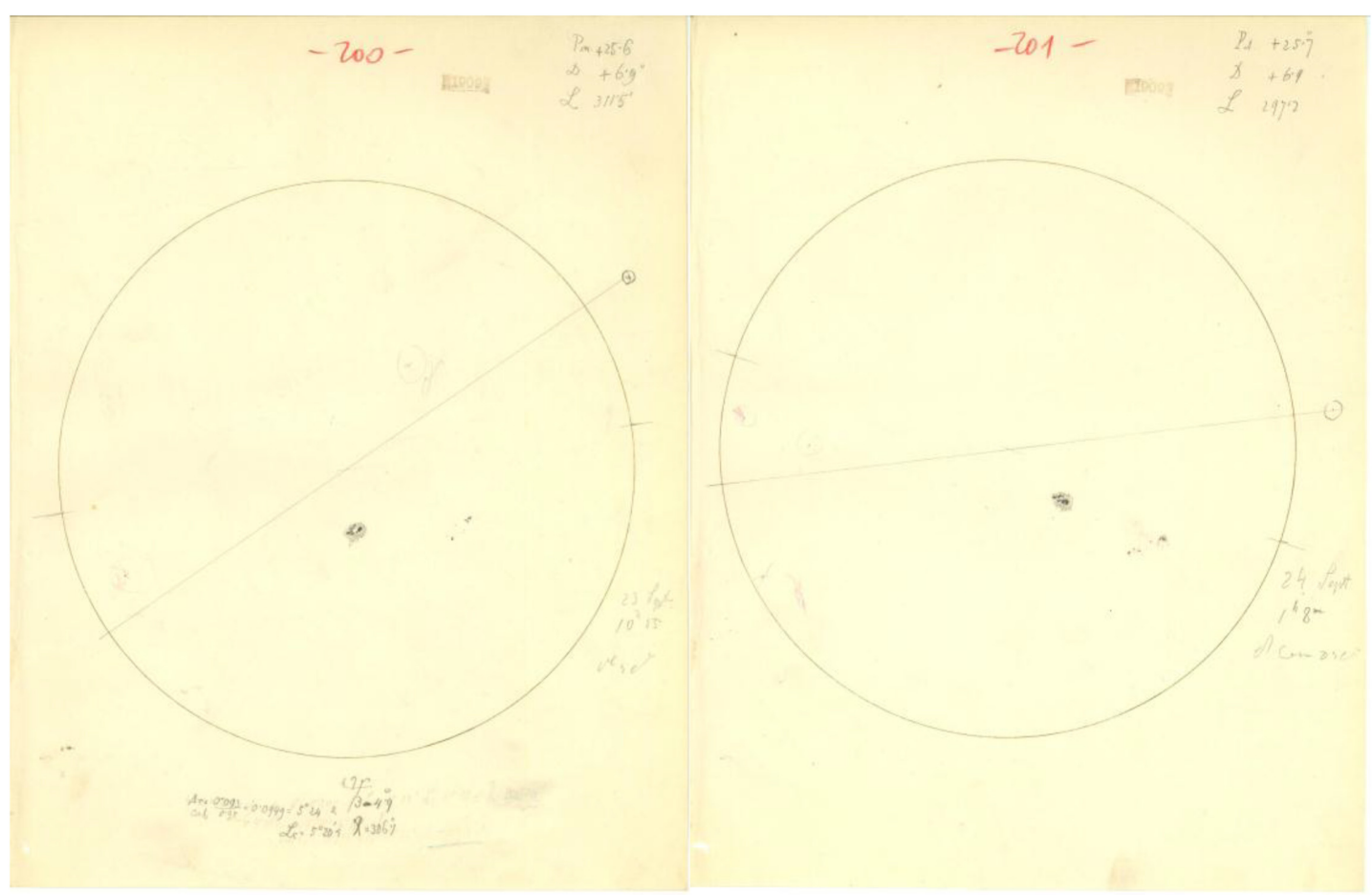

Figure 8. Sunspot drawings from Kalocsa Observatory on 23 (left) and 24 (right) September digitized by Baranyi, Györi \& Ludmány (2016). 
(frequently mentioned as 'two elliptical umbræ' in the sunspot by Lockyer 1909) share a penumbra in the sunspot drawing of the Kalocsa Observatory.

Fig. 7 shows the two flare ribbons extended from the centre of two umbrae to the outer edge of the sunspot group with a spiral shape. This interpretation is also confirmed by Lockyer $(1909$, p.15) who describes 'the two dark elliptical umbræ' with 'two bright portions stretching across and nearly meeting in the centre' at 11:11:47 GMT. This appearance may show us that the flare occurred along the magnetic neutral line stretching from the spot centre to the spot edge on the right-above side. If correct, this sunspot group should be categorized as the Type 1 region of Zirin \& Liggett (1987) and the Spot-spot case of Toriumi et al. (2017).

\subsection{Scaling the solar flare size}

As shown above, flaring activity in Greenwich sunspot group 6728 lasted from $\sim 10: 05-12: 20$ GMT and was accompanied by an $\sim-40 \mathrm{nT}$ geomagnetic crochet observed at Greenwich from 11:00-12:30 GMT (Love, Hayakawa \& Cliver 2019). The sudden commencement (SC) was observed at $\sim 11: 42-45$ GMT (Fig. 5; Jones 1955; Mayaud 1975). Mayaud (1975) reports an SC with an amplitude of $101 \mathrm{nT}$ observed at 11:42 GMT at Alibag Observatory. Hale (1931) reports a storm onset at 11:43 GMT from Kew Observatory. Fig. 5 reproduced from Uchida (1909) shows the SC at $\sim 20: 45$ LT (11:45 UT). These reports yield the Sun-Earth transit time (SFE to SC) of $24 \mathrm{~h} 42-45 \mathrm{~m}$, and an average speed of $\sim 1700 \mathrm{~km} \mathrm{~s}^{-1}$ (cf., Love, Hayakawa \& Cliver 2019).

CMEs in interplanetary space are known to be decelerated mainly due to dynamic drag force (Cargill et al. 1996; Manchester et al. 2004; Vršnak et al. 2013, Takahashi \& Shibata 2017). Takahashi \& Shibata (2017) showed that the deceleration is caused by the accumulation of sheath plasmas ahead of the CMEs. They showed an analytic expression of CME Sun-Earth travel time in terms of its mass and speed near the Sun and validated their model with observations.

Based on their model and the CME propagation time of $24 \mathrm{~h}$ $45 \mathrm{~min}$ in the event, the lower limit of the CME kinetic energy is estimated to be $1.5 \times 10^{33} \mathrm{erg}$, assuming that the upstream solar wind is slow $\left(350 \mathrm{~km} \mathrm{~s}^{-1}\right)$ and dense $\left(\sim 9 \mathrm{~cm}^{-3}\right)$. For this circumstance, a CME energy of $1.5 \times 10^{33} \mathrm{erg}$ suggests that the associated flare is of soft X-ray (SXR) class ¿X10, according to the procedure of Takahashi \& Shibata (2017). Alternatively, for a fast $\left(500 \mathrm{~km} \mathrm{~s}^{-1}\right)$ and rarified $\left(1 \mathrm{~cm}^{-3}\right)$ ambient solar wind, the lower limit of the CME kinetic energy is estimated to be $1.4 \times 10^{32} \mathrm{erg}$, which suggests that the SXR source flare was $\gtrsim X 1$ class.

The two modern solar-terrestrial events that are most similar to the 1909 event in terms of their flare locations and CME transit times to the Earth (based on Gopalswamy et al. 2005c) were those with flares on 14 July 2000 (W07; 27.9 h; initial CME speed $=1674 \mathrm{~km} \mathrm{~s}^{-1}$ ) and 29 October $2003($ W09; $19.7 \mathrm{~h}$; initial CME speed $=2029 \mathrm{~km} \mathrm{~s}^{-1}$ ) versus $\mathrm{W} 10,24.75 \mathrm{~h}$, and $\sim 1700 \mathrm{~km} \mathrm{~s}^{-1}$ for 24 September 1909. The Bastille Day flare in 2000 was an X5.7 event, while the second great flare in the 2003 Halloween sequence (Gopalswamy et al. 2005b) had an X10.0 SXR classification. The Bastille Day flare was preceded by an $\mathrm{X} 1$ class flare and halo CME $\left(1086 \mathrm{~km} \mathrm{~s}^{-1}\right)$ from the same region (AR9077) on 11 July 2000 (10:18UT) and the Halloween flare on 29 October was preceded by an X17 class flare and halo CME $\left(2459 \mathrm{~km} \mathrm{~s}^{-1}\right)$ on 28 October (11:10UT) also from the same active region (AR10486) (Yashiro et al. 2004). The CMEs launched from these earlier flares presumably assisted in the relatively rapid transit times to Earth of the 14 July $2000 \mathrm{CME}(27.9 \mathrm{~h})$ and the 29 October $2003 \mathrm{CME}(19.7 \mathrm{~h})$ by clearing out the plasma in its path. Time series for the geomagnetic aa index (Mayaud, 1972; http://www.geomag.bgs.ac.uk/cgi-bin/aaindex) as well as solar wind data (https://omniweb.gsfc.nasa.gov/ow.html) for the 14 July 2000 (data unavailable for the 29 October 2003 event) suggest that the Earth was in fast/rarified flows for both of these events. Thus the estimated lower limit SXR class for both of these events from the Takahashi \& Shibata (2017) model is $\gtrsim X 1$, somewhat below the observed values of X5.7 (14 July 2000) and X10 (29 October 2003).

Jones (1955) and Hale (1931) reported the 24 September 1909 event as the first flare in his monitoring. No great magnetic storms were recorded beforehand either (Jones 1955), unlike, e.g. 1859 (Jones 1955; Green \& Boardsen 2006; Nevanlinna 2008; Hayakawa et al. 2018b). (It should be noted that absence of evidence is not evidence of absence, as flares may have been overlooked or the associated CMEs were not geo-effective.) The aa record on 25 September, prior to the onset of the geomagnetic storm, shows low activity, consistent with slow solar wind (Mayaud 1972). Thus, based on the above transit time estimate of flare size for a slow dense solar wind and the comparison of the crochet amplitude of $\sim-40 \mathrm{nT}$ recorded at Greenwich for the 1909 flare with that observed for that 1859 Carrington flare $[-110 \mathrm{nT}$ at nearly the same time $(\sim 11: 15$ GMT), with an inferred SXR class of X42 (see Fig. 1 in Clarke et al. 2010)], we consider the 1909 flare as $\gtrsim X 10$ in SXR class.

\section{DISCUSSION}

\subsection{Scale of magnetic storm and auroral oval}

It is becoming increasingly clear that low-latitude auroral activity is a standard feature of extreme geomagnetic storms, i.e. those with minimum Dst values $\lesssim-500$ nT (e.g. Yokoyama et al. 1998; Shiokawa et al., 1997, 2002; Shiokawa, Ogawa \& Kamide 2005). The first clear indication that this was the case was for the Carrington storm of September 1859 for which Tsurutani et al. (2003) reported a sharp negative excursion in the Colaba H-component to $-1600 \pm 10 \mathrm{nT}$ followed by an equally rapid recovery. While the minimum Dst value those authors inferred for the 1859 event has become a topic of debate (Siscoe et al. 2006, Green \& Boardsen 2006; Cliver \& Dietrich 2013; Ngwira et al. 2014; Lakhina \& Tsurutani 2016; Tsurutani et al. 2018), the reality and character of the sharp negative spike that occurred at the beginning of the storm in conjunction with low-latitude aurora, similar to the 1909 event, has not. For the March 1989 event, strong negative (or positive) excursions in the $\mathrm{H}$-traces of low-latitude magnetograms did not occur near the beginning of the storm, but they did appear near the peak of the storm (time of minimum Dst; Fig. 6) concomitant with the most equatorward excursion of the aurora as determined by satellite measurements of electron precipitation (see Fig. 1 of Yokoyama et al. 1998). For the 1921 event (Silverman \& Cliver 2001; Kappenman 2006), an aurora observed by the staff at Apia, Samoa magnetic station coincided with a strong positive bay recorded at that observatory (Cliver \& Dietrich 2013). The occurrence of simultaneous sharp negative and positive $\mathrm{H}$ excursions at widely separated low-latitude observatories at the same time as low-latitude aurora, such as was the case for the 1909 event (Love, Hayakawa \& Cliver 2019), is more readily explained in terms of field-aligned currents, polar cap currents, and the auroral currents they drive than by ring currents that have longer recovery time currents. While other possible explanations 
have been proposed (e.g. Li et al. 2006; Tsurutani et al. 2018) for the concurrence of low-latitude aurora and concomitant negative spikes in magnetometer $\mathrm{H}$-traces, the 1909 event adds to the growing evidence for the non-ring-current picture that was first strongly advocated by Green \& Boardsen (2006).

\subsection{Colour and brightness of auroral display}

The colour of this auroral display is described as mostly reddish, as shown in Table 1. However, some auroral reports show appearances in non-reddish colour. The records $\mathrm{J} 1-1$ and $\mathrm{J} 12$ (N41 ${ }^{\circ} 58^{\prime}$, E $140^{\circ} 07^{\prime} ; 31.8^{\circ}$ MLAT) state that Sawada saw a transition from 'spherical light in bluish white colour through clouds' to light 'as reddish as pickled plums' with 'whitish striation' later. His description explicitly shows that the auroral display started without a reddish component. Another record J3-6 (N43 $04^{\prime}$, E $141^{\circ} 20^{\prime}$; $33.0^{\circ} \mathrm{MLAT}$ ) also states a transition from 'white light occupying one region' and 'several strokes of twinkling blue-white flash' since 24:00 LT to 'the sky became crimson' around 03:00 LT (26 September). Another report (J3-11) states that the auroral display 'shone in the sky seen like a fire, with its colour whitish' at Date (N42 $20^{\prime}$, E $140^{\circ} 59^{\prime} ; 32.2^{\circ}$ MLAT).

The transition from 'light in bluish white colour' to light 'as reddish as pickled plums' may be attributed to the transition from the sunlit aurora to the usual reddish aurora. The sunlit aurora can extend as high as $1100 \mathrm{~km}$ (Størmer 1955, pp.91-92; Hunten 2003), and the $\mathrm{N}_{2}{ }^{+} 1 \mathrm{NG}$ bands, including $427.8 \mathrm{~nm}$, are dominant (corresponding to the blue colour). Here, we use the height of $600 \mathrm{~km}$ for sunlit aurora, as its occurrence frequency becomes about $1 / 100$ of its peak value at this height (Størmer 1955, pp.9192). The emission of the the $\mathrm{N}_{2}{ }^{+} 1 \mathrm{NG}$ bands in the sunlit aurora is thought to come from fluorescent scattering of sunlight. One mechanism for the sunlight aurora is as follows (Degen 1987): $\mathrm{N}_{2}$ is ionized by impact of precipitating electrons, and the solar-induced fluorescence of the ionized $\mathrm{N}_{2}{ }^{+}$is responsible for the emission at $427.8 \mathrm{~nm}$. The ionization cross-section of $\mathrm{N}_{2}$ peaks at $\sim 100 \mathrm{eV}$ (Rees 1989). Another mechanism is as follows (T. Sakanoi, private communication): $\mathrm{O}$ is ionized by impact of precipitating electrons, and charge exchange between the metastable $\mathrm{O}^{+}$and $\mathrm{N}_{2}$ produces $\mathrm{N}_{2}{ }^{+}$, which gives rise to the emission at $427.8 \mathrm{~nm}$ due to solarinduced fluorescence. The ionization cross-section of $\mathrm{O}$ peaks at $\sim 70 \mathrm{eV}$ (Rees 1989).

Fig. 9 shows the location of the terminator at the altitude $600 \mathrm{~km}$ (thick line) and the location at which the solar elevation angle is $-12^{\circ}$ on the ground (thin line with ' -12 ', border of the astronomical twilight on the ground) at 15:00 UT (24:00 LT), and 17:00 UT (26:00 LT). It is considered that the sunlit aurora would have shone between the thick and thin lines if electrons were precipitating. The ellipse-like line shows the limit at which the aurora at altitude of $600 \mathrm{~km}$ is visible from the red point in Fig. 9,

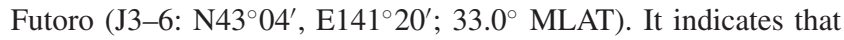
the observers at Futoro (J3) and Otobe (J1-1) may plausibly have seen the sunlit aurora. Note that the sunlit aurora could be visible when the auroral height was at least $540 \mathrm{~km}$. The 'light in bluish white colour' started to appear at the latest at 15:00 UT (24:00 LT). At this moment, the storm main phase was ongoing (Figs 4 and 5), and soft electrons are thought to precipitate into the sunlit upper atmosphere as low as around $55^{\circ}$ ILAT, resulting in the generation of the sunlit aurora. Then, as the storm main phase develops, the electron precipitation region is thought to move to lower ILATs where the upper atmosphere is in the dark. These precipitating electrons into the dark upper atmosphere could result in the reddish aurora dominated by $630.0 \mathrm{~nm}$ as is commonly seen at low latitudes (Shiokawa, Ogawa \& Kamide 2005).

Note that Tinsley et al. (1984) explain bluish low-latitude aurorae 'without red tint' as excitation of the $\mathrm{N}_{2}{ }^{+}$first negative band by heavy neutrals or ions of $\mathrm{H}$ and $\mathrm{O}$ without sunlight. This may be a kind of 'ring current aurora', where precipitation of neutral $\mathrm{H}$ or $\mathrm{H}^{+}$excites the $\mathrm{N}_{2}{ }^{+}$first negative band at low/mid latitudes during large magnetic storms (Zhang et al. 2006). A possible problem with this explanation is that ring current aurora is not bright and would be difficult to see with naked eyes.

This 1909 auroral display was frequently compared with a 'fire' or 'conflagration'. An observer at Sapporo Meteorological Observatory reported that he 'at first considered it as a firelight reflected in the sky' (J2-1). An observer at Ishinomaki Meteorological Observatory reported 'the sky was totally burnt so that it was bright enough to recognize objects' (J2-6). The observer at Matsuyama Meteorological Observatory (J2-8) wrote 'The observatory considered this as a conflagration. However, following surveys told us there were no conflagrations north from this place and saw newspapers ... and considered it as auroral borealis'.

It is known that bright auroral displays are frequently misinterpreted as conflagrations or fires (Green et al. 2006; Odenwald 2007; Silverman 2008; Vaquero et al. 2008; Hayakawa et al. 2016b). We can classify auroral brightness in terms of the International Brightness Coefficient (IBC) Class IV, whose total illumination on the ground corresponds with that of the full moon (Chamberlain 1961). It should be noted that the lunar phase was 0.38 and close to the full moon $(0.5)$ on 29 September according to the code of Kawamura et al. (2016). Thus the auroral display was bright enough to compete with the notable moonlight. Ebihara et al. (2017) examine a case of great auroral display on 17 September 1770 and consider precipitation of high-intensity low-energy electrons in mid- to low-latitude area, as a probable cause of that extremely bright display.

\subsection{Context of this extreme space weather event}

This event occurred two years after the solar cycle 14 with its maximum in 1907 (Clette et al. 2014; Svalgaard \& Schatten 2016). Fig. 10 shows the plot of monthly mean value of international sunspot number by the Sunspot Index and Long-term Solar Observation (Clette et al. 2014) for cycle 14. These plots show that this space weather event occurred in a declining phase of the cycle as expected for large space weather events (Lefèvre et al. 2016), while the cycle itself is relatively moderate even in its maximum and considered as a space weather event by a relatively quiet Sun (Kilpua et al. 2015).

Accordingly, the number of sunspot groups were only 3-5 on 24 September 1909 (Vaquero et al. 2016), and the sunspot area of region 6728 was moderate $(619 \mathrm{msh})$. However, even for this moderate solar activity state, the Sun can cause a quite geo-effective space weather event, if it has enough magnetic energy and emits a CME from disc centre.

Moreover, the reports in time reveal the sunspot group 6728 was active around this event. Lockyer (1909, p.14) reports increase of 'the intensity of the flocculus' at 12:12:10 UT on 21 September, and at 10:42:02 UT on 22 September, suggesting the magnetic activity of this sunspot group had been already intensive. Other reports on 'a bright crescent' at 11:50:26 UT on 17 September and 'two umbrae separated by an unusual bright streak' at 10:28:36 UT on 18 September might be interpreted as a jet eruption above the light bridge (Roy 1973; Shimizu et al. 2009; Toriumi, Katsukawa \& 


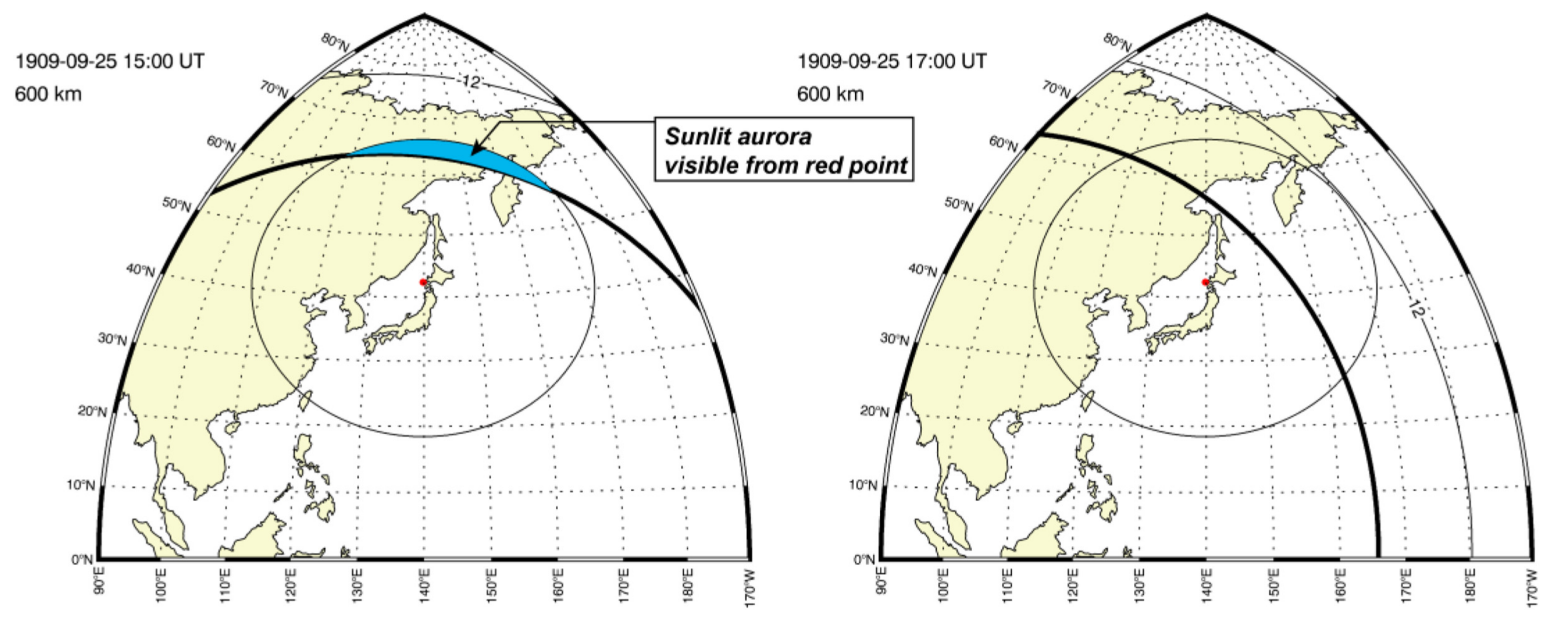

Figure 9. Location of the terminator at the altitude $600 \mathrm{~km}$ (thick line) and the location at which the solar elevation angle is $-12^{\circ}$ on the ground (thin line with ' -12 ', border of the astronomical twilight) at 15:00 UT (24:00 LT), and 17:00 UT (26:00 LT) on 25 September.

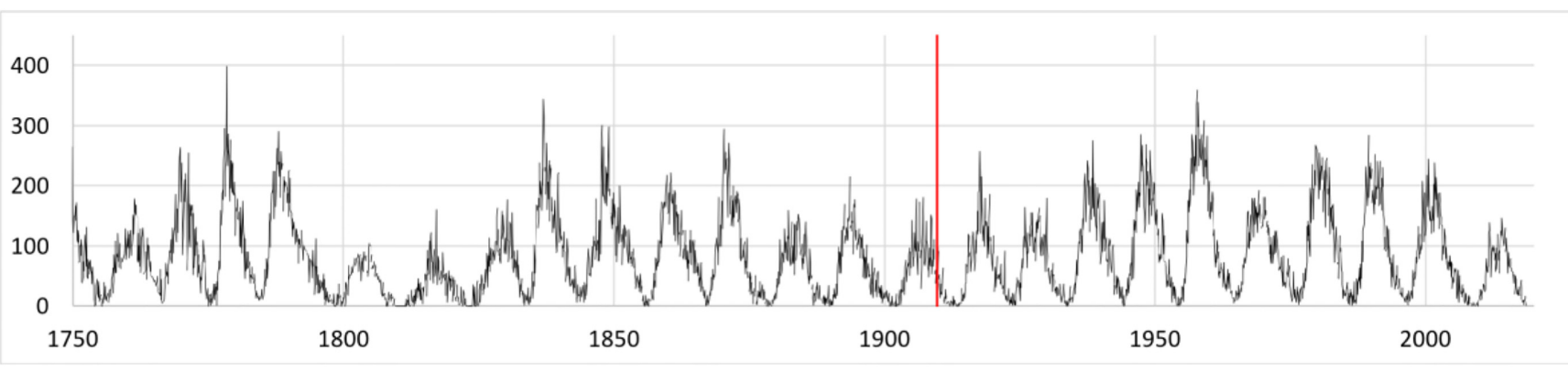

Figure 10. Context of the extreme space weather event on 25 September 1909, in comparison with the international sunspot number based on the data base of SILSO (Clette et al. 2014). The vertical axis shows the international sunspot number and the horizontal axis shows time series. The timing of the extreme space weather event on 25 September 1909 , is shown by a red stroke.

Cheung 2015a,b), although its relationship with the eventual flare is not clear. After the flare on 24 September, another flare was reported on 28 September by Evershed (1910) at the Kodaikanal Observatory $\left(\mathrm{N} 10^{\circ} 14^{\prime}, \mathrm{E} 077^{\circ} 28^{\prime}\right)$. His first assistant Sitrama Aiyar witnessed 'an outburst directly over the umbra of the spot' between 10:30 and 11:30 in Indian Standard Time, namely between $5 \mathrm{~h}$ and $6 \mathrm{~h}$ in GMT. Therefore, we consider that this sunspot group has emitted the flares and CMEs more than once as expected for intensive active regions (e.g. Tsurutani et al., 2007, 2008; Cliver \& Dietrich 2013).

In terms of cycle phase and associated active region, the 1909 space weather event is comparable to largest storm of Halloween 2003 sequence (Gopalswamy et al. 2005a,b). The November 2003 storm occurred $\sim 5 \mathrm{yr}$ prior to the end of cycle 24 , which is often compared to cycle 14 during which the September 1909 storm occurred $\sim 4$ yr before solar minimum. The 18 November 2003 eruption originated in an active region with total corrected spot area of $410 \mathrm{msh}$ and produced a storm with a minimum Dst value of $-422 \mathrm{nT}$.

\section{CONCLUSION}

A comparison of magnetic records and ground-based auroral observations for the great geomagnetic storm of 25 September 1909 (estimated Dst $=-595$ nT; Love, Hayakawa \& Cliver 2019) shows that the mid- and low-latitude aurorae, which were observed down to $\sim 23^{\circ}$ MLAT in Japan and $\sim-32^{\circ}$ MLAT at Carnarvon Farm in South Africa, occurred during the main phase and the early recovery phase of the magnetic storm. The Japanese reports indicate that the equatorward boundary of the auroral oval (or auroral region) extended to $31^{\circ}-35^{\circ}$ ILAT (based on an assumed auroral height of $400 \mathrm{~km})$, or $37^{\circ}-38^{\circ}(800 \mathrm{~km})$. In Japan, bluish colour was witnessed first, followed by a reddish one. The change from the bluish colour to the reddish one can be attributed to the transition from the sunlit aurora to the usual reddish aurora. Telegraph communications were disturbed in the Japanese domestic lines and the international line between Tokyo and Guam. The telegraphic disruptions were probably caused by the intensification of the storm-time ring current and the substorm current wedge. The 13/14 March 1989 storm had a comparable minimum Dst value of $-589 \mathrm{nT}$ and an equatorward boundary of auroral oval of $40^{\circ}$ MLAT that was based on satellite measurements. From the 24.75 hour interval between the SFE and the SC for September 1909 space weather event - nd the inferred solar wind conditions at Earth prior to the CME arrival nd the $\sim 40 \mathrm{nT}$ amplitude of the flare-associated crochet, we estimate a SXR class of $\gtrsim$ X10 for the eruptive flare on 24 September.

\section{ACKNOWLEDGEMENTS}

We thank the World Data Center for Geomagnetism (Kyoto) and relevant magnetic stations (Apia, San Fernando, Maritius, Vieques, 
Tokyo, and Alibag) for providing their data for geomagnetic observations, Sunspot Index and Long-term Solar Observation for providing the data for international sunspot number, the Debrecen Observatory, T. Baranyi, and A. Ludmány for providing the sunspot drawings by Kalocsa Observatory and relevant details, F. Clette and S. Stankov for their advices on the magnetograms at Uccle Observatory, T. Sakanoi for his advices on bluish emissions, Sam Silverman for providing copies of auroral reports in JBAA, E. Joshua Rigler for his preliminary review, Janet L. Slate for her proofreading, and Peter Riley for his helpful comments. We also thank the support of the 'UCHUGAKU' project of the Unit of Synergetic Studies for Space, the Exploratory and Mission Research Projects of the Research Institute for Sustainable Humanosphere (PI: H. Isobe) and SPIRITS 2017 (PI: Y. Kano) of Kyoto University. This work was also supported by a Grant-in-Aid from the Ministry of Education, Culture, Sports, Science and Technology of Japan, Grant Number JP15H05816 (PI: S. Yoden), JP15H03732 (PI: Y. Ebihara), JP16H03955 (PI: K. Shibata), and JP15H05815 (PI: Y. Miyoshi), JP16K17671 (PI: S. Toriumi), JP15H05814 (PI: K. Ichimoto), and a Grant-in-Aid for JSPS Research Fellows JP17J06954 (PI: H. Hayakawa). This work was also supported by the U. S. Geological Survey Geomagnetism Program and the 'Extreme Space-Weather Events' program in the RAL Space Physics Department.

\section{REFERENCES}

Allen J., Frank L., Sauer H., Reiff P., 1989, EOS Trans. Am. Geophys. Unions, 70, 1479

Azcárate D. T., 1910. Anales del Instituto Y Observatorio De Marina De San Fernando, Seccion 2, Observaciones Meteorológicas, Magnéticas y Sísmicas, Año 1909, Sección Tipográfica del Observatorio, San Fernando

Baker D. N., Li X., Pulkkinen A., Ngwira C. M., Mays M. L., Galvin A. B., Simunac K. D. C., 2013, Space Weather, 11, 585

Baker D. N. et al., 2008, Severe Space Weather Events-Understanding Societal and Economic Impacts. National Academies Press, Washington $\mathrm{DC}$

Baranyi T., Györi L., Ludmány A., 2016, Sol. Phys., 291, 3081

Bartels J., 1937, Terrestrial Magnetism and Atmospheric Electricity, 42, 235

Boteler D. H., 2006, Adv. Space Res., 38, 159

Cargill P. J., Chen J., Spicer D. S., Zalesak S. T., 1996, J. Geophys. Res., 101,4855

Carrington R. C., 1860, MNRAS, 20, 13

Chamberlain J. W., 1961, Physics of the Aurora and Airglow. Academic Press, New York, pp. 124

Chapman S., 1957a, Nature, 179, 7

Chapman S., 1957b, Bull. Nat. Inst. Sci. India, 9, 180

Chapman S., 1957c, Ann. IGY, 4, 25

Cid C., Palacios J., Saiz E., Guerrero A., Cerrato Y., 2014, J. Space Weather Space Clim., 4, A28

Clarke E., Rodger C., Clilverd M., Humphries M., Baillie O., Thomson M., 2010, An estimation of the Carrington flare magnitude from solar flare effects (SFE) in the geomagnetic records, RAS National Astronomy Meeting Glasgow, Scotland April 2010 Session: MIST Science Session P28

Claxton T. F., Walter A., 1913. Results of the Magnetical and Meteorological Observations Made at the Royal Alfred Observatory, Mauritius in the Year 1909. Government Printing Office, Mauritius

Clette F., Svalgaard L., Vaquero J. M., Cliver E. W., 2014, Space Sci. Rev. 186,35

Cliver E. W., 1995, Sol. Phys., 157, 285

Cliver E. W., Dietrich D. F., 2013, J. Space Weather Space Clim., 3, A31

Cliver E. W., Svalgaard L., 2004, Sol. Phys., 224, 407
Curto J. J., Castell J., Del Moral F., 2016, J. Space Weather Space Clim., 6, A23

Daglis I. A., 2000, Space Storm and Space Weather Hazards. Kluwer Academic Press, Amsterdam

Daglis I. A., 2004, Effects of space Weather on Technology Infrastructure. Kluwer Academic Press, Amsterdam

Degen V., 1987, Planet Space Sci., 35, 1061

Dyer C., Hands A., Ryden K., Lei F., 2018, IEEE Transactions on Nuclear Science, 65, 432

Ebihara Y., Ejiri M., 2000, J. Geophys. Res., 105, 15843

Ebihara Y., Hayakawa H., Iwahashi K., Tamazawa H., Kawamura A. D., Isobe H., 2017, Space Weather, 15, 1373

Eddie L. A., 1909, J. British Astron. Assoc., 20, 40

Evershed J., 1910, Kodaikanal Obs. Bull., 22, 265

Fowler A., 1909, Nature, 81, 395

Gonzalez W. D., Joselyn J. A., Kamide Y., Kroehl H. W., Rostoker G., Tsurutani B. T., Vasyliunas V. M., 1994, J. Geophys. Res., 99, 5771

Gopalswamy N., Barbieri L., Cliver E. W., Lu G., Plunkett S. P., Skoug R. M., 2005b, J. Geophys. Res., 110, CiteID A09S00

Gopalswamy N., Lara A., Manoharan P. K., Howard R. A., 2005a, Adv. Space Res., 36, 2289

Gopalswamy N., Yashiro S., Liu Y., Michalek G., Vourlidas A., Kaiser M. L., Howard R. A., 2005c, J. Geophys. Res., 110, A09S15

Gosling J. T., McComas D. J., Phillips J. L., Bame S. J., 1991, J. Geophys. Res., 96, 7831

Green J., Boardsen S., 2006, Adv. Space Res., 38, 130

Green J., Boardsen S., Odenwald S., Humble J., Pazamickas K., 2006, Adv. Space Res., 38, 145

Hale G. E., 1931, Astrophys. J., 73, 379

Hapgood M., 2011, Adv. Space Res., 47, 2059

Hapgood M., 2012, Nature, 484, 311

Hayakawa H. et al., 2016d, PASJ, 68, 99

Hayakawa H. et al., 2017e, ApJ, 850, L31

Hayakawa H. et al., 2018a, A\&A, 616, 11

Hayakawa H. et al., 2018b, ApJ, 862, 15

Hayakawa H. et al., 2018c, ApJ, 869, 57

Hazard D. L., 1912, Results of Observations Made at the Coast and Geodetic Survey Magnetic Observatory at Vieques, Porto Rico, 1909 and 1910, Department of Commerce, Govt. Printing Office, Washington, DC

Hodgson R., 1860, MNRAS, 20, 15

Holmes F., 1909, Observatory, 32, 396

Hopkinson G. W., 1909, S. Afr. J. Sci., 6, 68

Hunten D. M., 2003, Planet Space Sci., 51, 887

Jackson A., Jonkers A. R. T., Walker M. R., 2000, Roy. Soc. of London Phil. Tr. A, 358, 957

Jones H. S., 1955, Sunspot and Geomagnetic-Storm Data: Derived from Greenwich Observations, 1874-1954. H.M. Stationery Off., London

Kaiser M. L., Kucera T. A., Davila J. M., St. Cyr O. C., Guhathakurta M., Christian E., 2008, Space Science Reviews, 136, 5

Kanda S., 1933, Tenmon Geppou, 26, 204

Kappenman J. G., 2004, in Daglis I. A., ed., Effects of Space Weather on Technology Infrastructure. pp. 257, Kluwer Acad., Dordrecht, Netherlands

Kappenman J. G., 2006, Adv. Space Res., 38, 188

Kawamura A. D., Hayakawa H., Tamazawa H., Miyahara H., Isobe H., 2016, Publications of the Astronomical Society of Japan, 68, 79

Kilpua E. K. J. et al., 2015, ApJ, 806, 272

Kimball D. S., 1960, A Study of the Aurora of 1859, Sci. Rep. No. 6, University of Alaska, No. 6

Knipp D. J. et al., 2016, Space Weather, 14, 614

Kyoto M. N., Iyemori T., Sugiura M., Kamei T., World Data Center for Geomagnetism, 2015, Geomagnetic Dst index

Künzel H., 1960, Astron. Nachr., 285, 271

Lakhina G. S., Tsurutani B. T., 2016, Geosci. Lett., 3, 5

Lefèvre L., Aparicio A. J. P., Gallego M. C., Vaquero J. M., 2016, Sol. Phys., 291,260

Liu Y. D. et al., 2014, Nat. Commun., 5, 3481

Li X., Temerin M., Tsurutani B. T., Alex S., 2006, AdSpR, 38, 273 
Lockwood M., Bentley S., Owens M. J., Barnard L. A., Scott C. J., Watt C. E., Allanson O., Freeman M. P., 2018, Space Weather

Lockwood M., Owens M. J., Barnard L., Scott C. J., Usoskin I. G., Nevanlinna H., 2016, Sol. Phys., 291, 2811

Lockyer W. J. S., 1909, MNRAS, 70, 12

Loomis E., 1861, American Journal of Science, 96, 318

Love J. J., Hayakawa H., Cliver E. W., 2019, Space Weather, 16, 37

Manchester W. B., Gombosi T. I., Roussev I., Ridley A., de Zeeuw D. L., Sokolov I. V., Powell K. G., Tóth G., 2004, J. Geophys. Res., 109, A02107

Mayaud P. N., 1972, JGR, 77, 6870

Mayaud P. N., 1975, J. Geophys. Res., 80, 111

McPherron R. L., Russell C. T., Aubry M., 1973, J. Geophys. Res., 78, 3131

Nakazawa Y., Okada T., Shiokawa K., 2004, Earth Planets Space, 56, e41

Nevanlinna H., 2008, AdSpR, 42, 171

Newton H. W., 1943, MNRAS, 103, 244

O’Brien B. J. et al., 1962, J. Geophys. Res., 67, 1209

Odenwald S., 2007, Space Weather, 5, S11005

Odenwald S., 2015, Solar Storms: 2000 Years of Human Calamity! Create Space, San Bernardini

Oughton E. et al., 2016, Helios Solar Storm Scenario. Centre for Risk Studies, Univ. Cambridge, Cambridge

Pulkkinen A., Bernabeu E., Eichner J., Beggan C., Thomson A. W. P., 2012, Space Weather, 10, 04003

Pytte T., Mcpherron R. L., Kokubun S., 1976, Planet Space Sci., 24, 1115

Rees M. H., 1989, Physics and Chemistry of the Upper Atmosphere. Cambridge University Press, Cambridge

Rich F., Denig W., 1992, Can. J. Phys., 70, 510

Riley P., 2012, Space Weather, 10, 02012

Riley P., Baker D., Liu Y. D., Verronen P., Singer H., Güdel M., 2018, Space Sci. Rev., 214, \#21

Riley P., Caplan R. M., Giacalone J., Lario D., Liu Y., 2016, ApJ, 819, 57

Riley P., Love J. J., 2017, Space Weather, 15, 53

Roy J. R., 1973, Solar Physics, 28, 95

Russell C. T., et al., 2013, ApJ, 770, 38

Sawada T., 1928, Tenmon Geppou, 21, 132

Shimizu T., et al., 2009, ApJL, 696, L66

Shinbori A. et al., 2005, Earth Planet. Space

Shiokawa K., Meng C.-I., Reeves G. D., Rich F. J., Yumoto K., 1997, J. Geophys. Res., 102, 14237

Shiokawa K., Ogawa T., Kamide Y., 2005, J. Geophys. Res., 110, A05202

Shiokawa K. et al., 2002, J. Geophys. Res., 107, 1088

Silverman S. M., 1995, J. Atmos. Terr. Phys., 57, 673

Silverman S. M., 1998, J. Atmos. Sol. Terr. Phys., 60, 997

Silverman S. M., 2006a, Adv. Space Res., 38, 200

Silverman S. M., 2008, J. Atmos. Sol. Terr. Phys., 70, 1301

Silverman S. M., Cliver E. W., 2001, J. Atmos. Sol. Terr. Phys., 63, 523

Siscoe G., Crooker N. U., Clauer C. R., 2006, AdSpR, 38,173

Slocum F., 1910, Astrophys. J., 31, 26

Stewart B., 1861, Philosophical Transactions of the Royal Society of London, 151, 423

Størmer C., 1955, The Polar Aurora. Oxford University Press, Oxford

Svalgaard L., Schatten K. H., 2016, Solar Physics, 291, 2653

Takahashi T., Shibata K., 2017, ApJ, 837, L17

Temerin M., Li X., 2002, J. Geophys. Res., 107, 1472

Thébault E. et al., 2015, Earth Planets Space, 67, 79

Tinsley B. A. et al., 1984, Geophys. Res. Lett., 11, 572

Toriumi S., Katsukawa Y., Cheung M. C. M., 2015a, ApJ, 811, 137

Toriumi S., Katsukawa Y., Cheung M. C. M., 2015b, ApJ, 811, 138

Toriumi S., Schrijver C. J., Harra L. K., Hudson H., Nagashima K., 2017, ApJ, 834, 56

Tsubouchi K., Omura Y., 2007, Space Weather, 5, S12003

Tsurutani B. T., Gonzalez W. D., Lakhina G. S., Alex S., 2003, J. Geophys. Res., 108, 1268

Tsurutani B. T., Lakhina G. S., Echer E., Hajra R., Nayak C., Mannucci A. J., Meng X., 2018, J. Geophys. Res., 123, 1388

Tsurutani B. T. et al., 2007, J. Geophys. Res., 113, A05311

Tsurutani B. T. et al., 2008, J. Geophys. Res., 113, A05311
Uchida T., 1909. Denki Gakkai Zasshi, 29, 701

Usoskin I. G., 2017, Living Reviews in Solar Physics, 5, 1

Usoskin I. G., Kovaltsov G. A., 2012, The Astrophysical Journal, 757, 92

Vaquero J. M., Valente M. A., Trigo R. M., Ribeiro P., Gallego M. C., 2008, J. Geophys. Res., 113, A08230

Vaquero J. M., Vázquez M., 2009, Astrophys. Space Sci. Libr., 361

Vaquero J. M. et al., 2016, Sol. Phys., 291, 3061

Vršnak B. et al., 2013, Sol. Phys., 285, 295

Wegener K., 1914. Ergebnisse der Arbeiten des Samoa-Observatoriums, IX. Die erdmagnetischen Beobachtungen im Jahre 1909 und 1910. Weidmannsche Buchhandlung, Berlin

Willis D. M., Stephenson F. R., Fang H., 2007, Ann. Geophys., 25, 417

Willis D. M., Stephenson F. R., Singh J. R., 1996, Q. J. R. Astron. Soc., 37, 733

Yashiro S. et al., 2004, J. Geophys. Res., 109, A07105

Zhang Y., Paxton L. J., Kozyra J. U., Kil H., Brandt P. C., 2006, JGRA, 111, A09307

Zirin H., Liggett M. A., 1987, Sol. Phys., 113, 267

\section{APPENDIX: REFERENCES FOR CONTEMPORARY OBSERVATIONAL RECORDS}

J1-1: Tenmon Geppou, v. 21, pp.132-133 = Sawada (1928).

J1-2: Tenmon Geppou, v.8, p.88

J1-3: Tenmon Geppou, v.8, p.88

J1-4: Tenmon Geppou, v.8, p.88

J1-5: Tenmon Geppou, v.8, p.88

J2-1: Kishou Shusi, v.28, p.360

J2-2: Kishou Shusi, v.28, pp.360-361

J2-3: Kishou Shusi, v.28, p.361

J2-4: Kishou Shusi, v.28, p.361

J2-5: Kishou Shusi, v.28, pp.361-362

J2-6: Kishou Shusi, v.28, p.362

J2-7: Kishou Shusi, v.28, pp.362-363

J2-8: Kishou Shusi, v.28, p.363

J2-9: Kishou Shusi, v.28, p.363

J3-1: Chigaku Zasshi, v.22, p.111

J3-2: Chigaku Zasshi, v.22, p.111

J3-3: Chigaku Zasshi, v.22, p.111

J3-4: Chigaku Zasshi, v.22, p.111-112

J3-5: Chigaku Zasshi, v.22, pp.112-113

J3-6: Chigaku Zasshi, v.22, pp.113-114

J3-7: Chigaku Zasshi, v.22, p.114

J3-8: Chigaku Zasshi, v.22, p.114

J3-9: Chigaku Zasshi, v.22, p.115

J3-10: Chigaku Zasshi, v.22, p.115

J3-11: Chigaku Zasshi, v.22, p.115

J3-12: Chigaku Zasshi, v.22, pp.115-116

J3-13: Chigaku Zasshi, v.22, p.116

J3-14: Chigaku Zasshi, v.22, p.116

J3-15: Chigaku Zasshi, v.22, pp.116-117

J3-16: Chigaku Zasshi, v.22, p.117

J3-17: Chigaku Zasshi, v.22, p.117

J3-18: Chigaku Zasshi, v.22, p.117

J3-19: Chigaku Zasshi, v.22, pp.117-118

J3-20: Chigaku Zasshi, v.22, p.118

J3-21: Chigaku Zasshi, v.22, pp.118-119

J3-22: Chigaku Zasshi, v.22, p.119

J3-23: Chigaku Zasshi, v.22, p.119

J4: Niigata Shinbun, 1909-09-27, p.5

J5: Kahoku Shinpou, 1909-10-02 (original record of J3-18) 
J6: Jiji Shinpou, 1909-09-28, p.6 (original record of J1-2 and $\mathrm{J} 1-5)$

J7: Chugoku Shinbun, 1909-09-28, p.4

J8: Kishou Shushi, v.28, p.405-406

J9: Sado Shinbun, 1909-09-28, p.3

J10: Otaru Shinbun, 1909-09-27, p.3

J11: Hokkai Times, 1909-09-28, p.3

J12: The heavens, 8, 90, pp.423-424.

SA1: South African Journal of Science, v.6, pp.68-69 = Hopkinson (1909)

SA2: South African Journal of Science, v.6, p.69 = Hopkinson (1909)

SA3: Journal of British Astronomical Association, v.20, pp.4041 = Eddie (1909)

SA4: Rand Daily Mail, 1909-09-28

SA5: South African Journal of Science, v.6, p.69 = Hopkinson (1909)
AU1: Brisbane Courier, 1909-09-27, p.4

AU2: Brisbane Courier, 1909-09-27, p.4

AU3: Brisbane Courier, 1909-09-27, p.4

AU4: Brisbane Courier, 1909-09-27, p.4

AU5: Brisbane Courier, 1909-09-27, p.4

AU6: Warwick Examiner and Times, 1909-09-27, p. 8

AU7: Geraldton Express, 1 1909-10-1, p.1

AU8: Mount Magnet Miner and Lennonville Leader, 1909-10-2, p. 2

N1: Nature, v.81, p.524/The West Australian, 1909-09-27, p.7

N2: Nature, v.81, p.524/The West Australian, 1909-09-27, p.7

N3: Nature, v.81, p.524/The West Australian, 1909-09-27, p.7

N4: Nature, v.81, p.524/The West Australian, 1909-09-27, p.7

N5: Nature, v.81, p.524/The West Australian, 1909-09-27, p.7

This paper has been typeset from a $\mathrm{T}_{\mathrm{E}} \mathrm{X} / \mathrm{L} \mathrm{T} \mathrm{E} \mathrm{X}$ file prepared by the author. 